\title{
The mean composition of ocean ridge basalts
}

\section{Citation}

Gale, Allison, Colleen A. Dalton, Charles H. Langmuir, Yongjun Su, and Jean-Guy Schilling. 2013. "The Mean Composition of Ocean Ridge Basalts." Geochem. Geophys. Geosyst. 14, no. 3: 489518.

\section{Published Version}

doi:10.1029/2012GC004334

\section{Permanent link}

http://nrs.harvard.edu/urn-3:HUL.InstRepos:12363838

\section{Terms of Use}

This article was downloaded from Harvard University's DASH repository, and is made available under the terms and conditions applicable to Other Posted Material, as set forth at http:// nrs.harvard.edu/urn-3:HUL.InstRepos:dash.current.terms-of-use\#LAA

\section{Share Your Story}

The Harvard community has made this article openly available.

Please share how this access benefits you. Submit a story.

Accessibility 

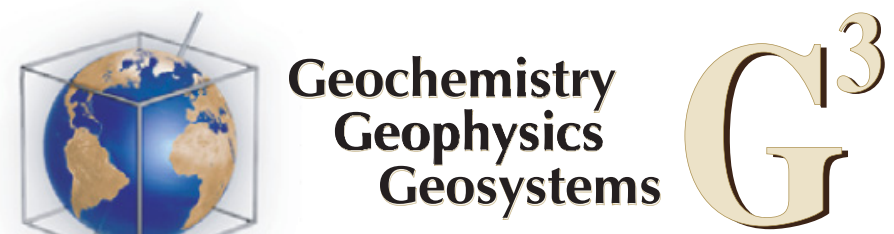

Article

Volume 14, Number 3

6 March 2013

doi:10.1029/2012GC004334

ISSN: $1525-2027$

Published by AGU and the Geochemical Society

\title{
The mean composition of ocean ridge basalts
}

\author{
Allison Gale \\ Department of Earth and Planetary Sciences, Harvard University, Cambridge, Massachusetts, USA \\ (agale23@gmail.com)
}

Colleen A. Dalton

Department of Earth and Environment, Boston University, Boston, Massachusetts, USA

\section{Charles H. Langmuir}

Department of Earth and Planetary Sciences, Harvard University, Cambridge, Massachusetts, USA

\section{Yongjun Su \\ Lamont-Doherty Earth Observatory and Department of Earth and Environmental Sciences, Columbia University, Palisades, New York, USA}

\author{
Jean-Guy Schilling \\ Graduate School of Oceanography, University of Rhode Island, Narragansett, Rhode Island, USA
}

[1] The mean composition of mid-ocean ridge basalts (MORB) is determined using a global data set of major elements, trace elements, and isotopes compiled from new and previously published data. A global catalog of 771 ridge segments, including their mean depth, length, and spreading rate enables calculation of average compositions for each segment. Segment averages allow weighting by segment length and spreading rate and reduce the bias introduced by uneven sampling. A bootstrapping statistical technique provides rigorous error estimates. Based on the characteristics of the data, we suggest a revised nomenclature for MORB. "ALL MORB" is the total composition of the crust apart from back-arc basins, N-MORB the most likely basalt composition encountered along the ridge $>500 \mathrm{~km}$ from hot spots, and D-MORB the depleted end-member. ALL MORB and N-MORB are substantially more enriched than early estimates of normal ridge basalts. The mean composition of back-arc spreading centers requires higher extents of melting and greater concentrations of fluid-mobile elements, reflecting the influence of water on back-arc petrogenesis. The average data permit a re-evaluation of several problems of global geochemistry. The K/U ratio reported here $(12,340 \pm 840)$ is in accord with previous estimates, much lower than the estimate of Arevalo et al. (2009). The low $\mathrm{Sm} / \mathrm{Nd}$ and ${ }^{143} \mathrm{Nd} /{ }^{144} \mathrm{Nd}$ ratio of ALL MORB and N-MORB provide constraints on the hypothesis that Earth has a non-chondritic primitive mantle. Either Earth is chondritic in $\mathrm{Sm} / \mathrm{Nd}$ and the hypothesis is incorrect or MORB preferentially sample an enriched reservoir, requiring a large depleted reservoir in the deep mantle.

Components: 18,000 words, 13 figures, 3 tables.

Keywords: MORB; basalt; trace element; major element; DMM.

Index Terms: 1021 Geochemistry: Composition of the oceanic crust.

Received 11 July 2012; Revised 11 December 2012; Accepted 11 December 2012; Published 6 March 2013.

Gale A., C. A. Dalton, C. H. Langmuir, Y. Su, and J.-G. Schilling (2013), The mean composition of ocean ridge basalts, Geochem. Geophys. Geosyst., 14, 489-518, doi:10.1029/2012GC004334. 


\section{Introduction}

[2] The global ocean ridge system stretches over $60,000 \mathrm{~km}$, randomly sampling the mantle while producing $75 \%$ of Earth's volcanism [Crisp, 1984] and creating two thirds of Earth's crustal area. The mean composition of mid-ocean ridge basalts (MORB), therefore, provides insights into the composition of Earth's most extensive crustal reservoir as well as the best available constraint on the composition of the upper mantle. Comparisons of the mean compositions from different regions are useful to address questions regarding the relative contributions of mantle temperature, mantle heterogeneity, and spreading rate to erupted MORB compositions, and the importance of spreading rate to both melting and fractionation.

[3] Early estimates of the average composition of MORB were calculated on a small number of samples [e.g., Hofmann, 1988; Sun and McDonough, 1989]. More recently, multiple groups have calculated averages using a more extensive set of compositions [Salters and Stracke, 2004; Rubin and Sinton, 2007; Arevalo and McDonough, 2010, hereafter referred to as $A M, 2010]$. These global studies, however, either averaged individual samples to estimate a mean composition [AM, 2010; Salters and Stracke, 2004], a method prone to sampling bias, or averaged samples from 37 "ridge sections" to explore variations with spreading rate without addressing the question of the global average composition [Rubin and Sinton, 2007].

[4] Su [2002], in an unpublished Ph.D. thesis, adopted a different approach by determining averages for individual segments. His study was hampered, however, by the lack of ready digital access to global bathymetric data. Like Rubin and Sinton [2007], Su [2002] released the segment averages and not the individual data, limiting future utility of the database. During the decade since his study, there has been a dramatic increase in the number of measured samples and particularly in the availability of ICP-MS trace element data, including some 1100 analyses from the Schilling (Kelley et al., 2013) and Langmuir laboratories (this study).

[5] In this paper, we present an updated mean composition of MORB and its various chemical and regional sub-varieties, with the following improvements over previous work: (1) the definition of 771 individual ridge segments that constitute the global ocean ridge system, (2) assignment of each sample to its proper ridge segment, (3) checks for data quality and application of interlaboratory corrections for major elements, (4) presentation of individual analyses as well as each segment mean, (5) a rigorous error analysis of the mean compositions to establish meaningful uncertainties, and (6) a substantially enhanced data set including 1800 previously unpublished major element analyses and 1100 previously unpublished high-quality ICP-MS trace element analyses from every ocean basin. The following sections address the creation of the database, the calculation of averages and their errors, and some of the implications for the composition and origin of major Earth reservoirs. Perhaps most importantly, the carefully compiled database is published in its entirety so that other investigators may make full use of it.

\section{Creating a Global MORB Database at the Segment Scale}

\subsection{Defining Ridge Segments}

[6] To calculate a global average based on segments, a global segment catalog is necessary. Ridges are segmented on a variety of length scales. At fast-spreading ridges, there can be "first-order" transform faults, or "second-order" non-transform offsets, or even "fourth-order" discontinuities that are slight "deviations from axial linearity" of the ridge axis that can also be chemical boundaries [Langmuir et al., 1986; Macdonald et al., 1991]. Such discrete ordering is less apparent, however, on slow and ultraslow spreading ridges. Accurate definition of segments in some regions is also hampered by bathymetry of widely varying quality (Figure 1). Despite these complexities, using GeoMapApp (www.geomapapp.org), we defined 771 individual ridge segments, including back-arc spreading centers. The level of defined segmentation corresponds approximately to "second-order" segments, taking into account both ridge offsets and variations in axial depth along axis. Further details of the segment catalog will be found in a forthcoming manuscript (Langmuir, 2013). Segments are labeled with an identifier consisting of four letters followed by numbers. For example, SWIR12 indicates that the segment is the twelfth segment along the Southwest Indian Ridge. The full catalog of ridge segments is provided in the Supporting Information. ${ }^{1}$

[7] The total length of the global ridge system so defined is $60,864 \mathrm{~km}$. The length of individual

${ }^{1}$ All Supporting Information may be found in the online version of this article. 

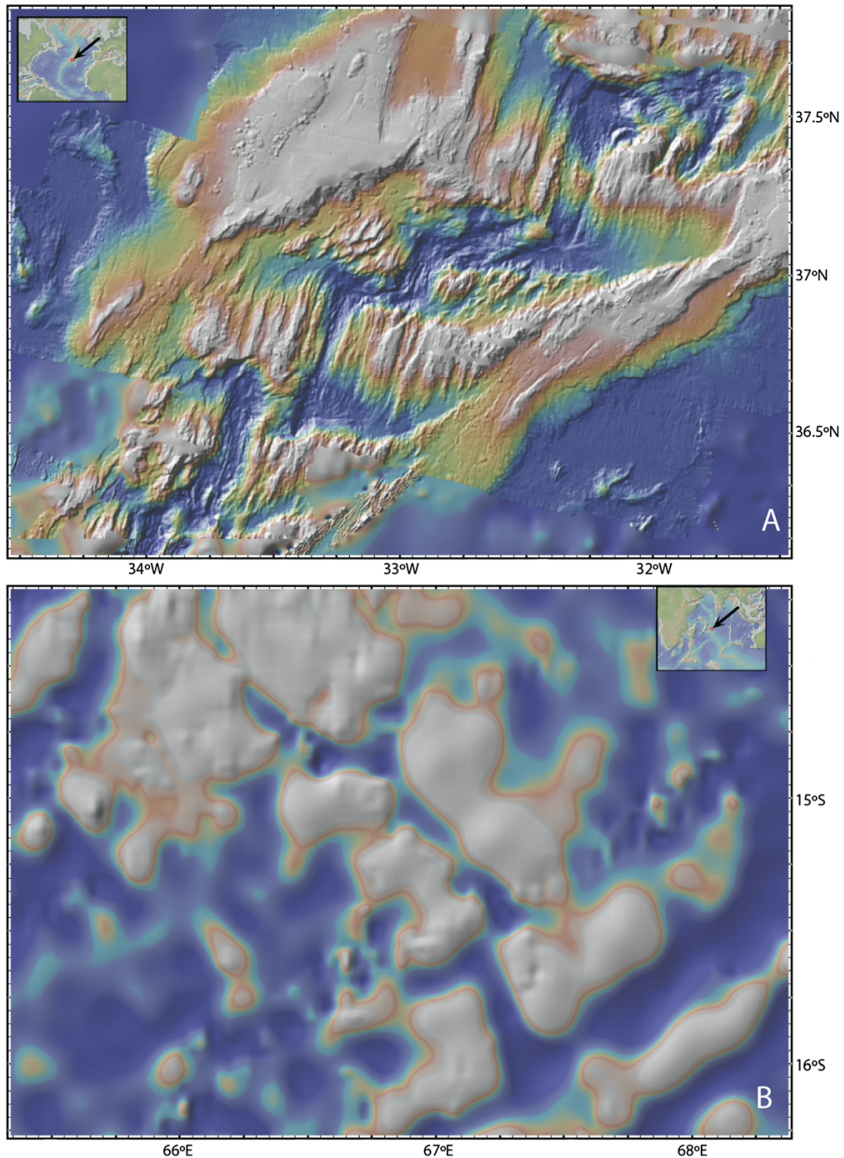

Figure 1. Examples of bathymetry available from the software GeoMapApp. (A) A region of the Mid-Atlantic Ridge $\left(36^{\circ}-37^{\circ} \mathrm{N}\right)$ with high-quality, multi-beam bathymetry [Cannat et al., 1999; Escartin et al., 2001]. (B) A region of the Central Indian Ridge $\left(14^{\circ}-16^{\circ} \mathrm{S}\right)$ where only satellite bathymetry is publicly available. Both regions are shown at approximately the same scale. Segment selection is easier along sections of the ridge for which high-quality bathymetry is available.

segments ranges from 6.6 to $375.8 \mathrm{~km}$, with a median length of $66.7 \mathrm{~km}$, and the mean segment depth ranges from $5382 \mathrm{~m}$ below sea level along the Mid-Cayman spreading center to $1025 \mathrm{~m}$ above sea level at Iceland. For 692 of the 771 ridge segments, spreading rate was calculated at the midpoint of each segment using the rotation poles and angular velocities from NUVEL-1A [DeMets et al., 1994] and the equations for relative motion on a plate boundary [e.g., Fowler, 2008]. Spreading rates for back-arc spreading centers and the Juan de Fuca ridge were calculated from NR-MORVEL56 [Argus et al., 2011], which includes the plate motions of 31 additional small plates defined by Bird [2003].

\subsection{Major Elements}

[8] Major element compositions were compiled from several sources, including PetDB [Lehnert et al., 2000], GeoROC (for sub-aerial Iceland sample data), and previously unpublished data. Data were downloaded from PetDB on 15 March 2010 with the only requirement that at least one major element oxide be reported. This resulted in an initial database of 36,734 glass and whole rock samples. From this compilation, samples from land outcrops (e.g., data from the Palisades Sill are included in PetDB) as well as Deep Sea Drilling Project (DSDP) and Ocean Drilling Program (ODP) samples were eliminated. Over 1800 previously unpublished analyses and 5512 analyses for Iceland from GeoRoc were added to the database. The updated compilation contained 33,695 samples. The paragraphs below outline the sequence of steps taken to eliminate questionable or inapplicable analyses and retain only the highest-quality data.

(1) Sample location. To assign each MORB sample to the appropriate segment, a polygon was defined around each segment, using a width of 
$10 \mathrm{~km}$ on either side of the segment axis. Any sample outside a polygon was excluded. In cases where samples appeared to be mislocated in PetDB (e.g., in Mexico), locations were corrected using original references. The segment assignment for each sample may be found in the Supporting Information.

(2) Complete set of oxides. For the major element data, each sample was required to have $\mathrm{Fe}$ (as $\mathrm{FeO}$ and/or $\mathrm{Fe}_{2} \mathrm{O}_{3}$ ), $\mathrm{SiO}_{2}, \mathrm{Al}_{2} \mathrm{O}_{3}, \mathrm{MgO}, \mathrm{TiO}_{2}$, $\mathrm{Na}_{2} \mathrm{O}, \mathrm{CaO}$, and $\mathrm{K}_{2} \mathrm{O}$. Duplicate samples, which possess identical locations and major element compositions, were eliminated. The "insegment" and major element selection criteria reduced the database to 16,964 samples. Fe required special attention in order to determine total $\mathrm{Fe}\left(\mathrm{FeO}_{\mathrm{T}}\right)$ because of the diverse forms in which it is reported in PetDB. If $\mathrm{FeO}_{\mathrm{T}}$ was reported, and then $\mathrm{FeO}_{\mathrm{T}}=\mathrm{FeO}_{\mathrm{T}}$. If $\mathrm{FeO}$ was reported and $\mathrm{Fe}_{2} \mathrm{O}_{3}$ was not, $\mathrm{FeO}_{\mathrm{T}}=\mathrm{FeO}$. If only $\mathrm{Fe}_{2} \mathrm{O}_{3 \mathrm{~T}}$ was reported, $\mathrm{FeO}_{\mathrm{T}}=0.9 * \mathrm{Fe}_{2} \mathrm{O}_{3 \mathrm{~T}}$. If both $\mathrm{FeO}$ and $\mathrm{Fe}_{2} \mathrm{O}_{3}$ were reported, $\mathrm{FeO}_{\mathrm{T}}=$ $\mathrm{FeO}+0.9 * \mathrm{Fe}_{2} \mathrm{O}_{3}$. If neither $\mathrm{FeO}$ nor $\mathrm{Fe}_{2} \mathrm{O}_{3 \mathrm{~T}}$ were reported and $\mathrm{Fe}_{2} \mathrm{O}_{3}$ was reported, $\mathrm{FeO}_{\mathrm{T}}=$ $0.9 * \mathrm{Fe}_{2} \mathrm{O}_{3}$.

(3) Interlaboratory bias. Because of analytical differences among laboratories, "interlaboratory bias correction factors" were applied to each analysis where possible (factors provided in Supporting Information). The interlaboratory correction factors were primarily derived from the extensive work of $S u$ [2002]. Because nearly half of the total major element database comes from either the Smithsonian (W. Melson) or Langmuir laboratories, however, we re-determined their interlaboratory correction factors. To do this, we analyzed VG-2, the Smithsonian glass standard, 195 times (in different sessions) as an unknown, and normalized it to the Langmuir laboratory in-house standard VE-32. We also obtained probe mounts containing sample glasses from Melson et al. [2002] and measured them using our procedures. Comparison of these analyses as well as analyses from both laboratories on samples from a given region (Figure 2) confirms the interlaboratory correction factors. Interlaboratory corrections could not be estimated for some laboratories, but over $92 \%$ of the glasses in the database have been corrected to a common basis.

(4) Igneous compositions and major-element sums. Data were then filtered to eliminate samples outside the igneous range (e.g., a number of palagonite analyses were present in the original data set). We retained samples with $\mathrm{SiO}_{2}=45-77 \quad$ wt. $\%, \quad \mathrm{Al}_{2} \mathrm{O}_{3}=10-19 \quad$ wt. $\%$, $\mathrm{MgO}<12$ wt. $\%, \mathrm{TiO}_{2}=0.5-5$ wt. $\%, \mathrm{FeO}_{\mathrm{T}}=$ 3-20 wt. \%, $\mathrm{CaO}<14$ wt. $\%, \mathrm{~K}_{2} \mathrm{O}<3$ wt.\%, and $\mathrm{Na}_{2} \mathrm{O}<6$ wt.\%. Eliminated analyses were then checked for misreported data in PetDB, and where errors were evident, adjustments were made based on the original papers. The final data quality filter involved a check of the major element sum $\left(\mathrm{FeO}_{\mathrm{T}}+\mathrm{SiO}_{2}+\mathrm{Al}_{2} \mathrm{O}_{3}+\right.$ $\mathrm{MgO}+\mathrm{TiO}_{2}+\mathrm{Na}_{2} \mathrm{O}+\mathrm{CaO}+\mathrm{K}_{2} \mathrm{O}+\mathrm{MnO}+$ $\mathrm{P}_{2} \mathrm{O}_{5}$ ). Since $\mathrm{MnO}$ and $\mathrm{P}_{2} \mathrm{O}_{5}$ are not analyzed by all laboratories (a notable example being the lack of $\mathrm{MnO}$ data from the Smithsonian), we calculated placeholder values strictly for the sum calculations $\left(\mathrm{MnO}=\mathrm{FeO}_{\mathrm{T}} / 54 ; \mathrm{P}_{2} \mathrm{O}_{5}\right.$ was estimated using a polynomial best-fit equation based on $\mathrm{K}_{2} \mathrm{O}$ contents). The sum was then calculated as defined above, and any analyses with sums $<98.5$ wt. $\%$ or $>101$ wt. $\%$ were eliminated.

(5) Estimating $\mathrm{H}_{2} \mathrm{O}$. Variable $\mathrm{H}_{2} \mathrm{O}$ contents can be significant, particularly for basalts from backarc spreading centers. $\mathrm{H}_{2} \mathrm{O}$ was estimated as $\mathrm{H}_{2} \mathrm{O}_{\text {est }}=1.5 * \mathrm{~K}_{2} \mathrm{O}$ [Langmuir et al., 2006] for open-ocean ridge basalts. For basalts from back arcs, the $\mathrm{H}_{2} \mathrm{O}_{\text {est }}$ formula was based on observed data, ranging from $14.1 * \mathrm{~K}_{2} \mathrm{O}$ in certain segments of the Lau basin to $2 * \mathrm{~K}_{2} \mathrm{O}$ for most of the segments in Scotia (see Supporting Information). For some high- $\mathrm{K}_{2} \mathrm{O}$ samples, $\mathrm{H}_{2} \mathrm{O}_{\text {est }}$ is larger than expected from the solubility of $\mathrm{H}_{2} \mathrm{O}$ in basaltic magmas. Solubility depends strongly on pressure of eruption, permitting calculation of a maximum $\mathrm{H}_{2} \mathrm{O}$ $\left(\mathrm{H}_{2} \mathrm{O}_{\text {max }}\right)$ for each sample based on its eruption depth [Dixon et al., 1995; Newman and Lowenstern, 2002]. In the rare cases where $\mathrm{H}_{2} \mathrm{O}_{\text {est }}$ was larger than $\mathrm{H}_{2} \mathrm{O}_{\max }(\sim 200$ glasses and 50 whole rocks), $\mathrm{H}_{2} \mathrm{O}_{\text {est }}=\mathrm{H}_{2} \mathrm{O}_{\text {max }}$.

(6) Renormalizing oxides. For the final data set, the measured oxide contents were re-normalized to a sum of $99.8 \mathrm{wt} . \%-\mathrm{H}_{2} \mathrm{O}_{\text {est }}$ for each sample. The selection of 99.8 wt.\% instead of $100 \%$ accounts for the presence of trace elements (e.g., $\mathrm{S}, \mathrm{Ni}, \mathrm{V}$, and $\mathrm{Cr}$ ) that are not included in the sum formula. Both the re-normalized and the raw data are provided in the Supporting Information.

[9] The total number of glass analyses in the final major element data set is 12,527 . For the $>1800$ new analyses being released with this study, major elements were collected by either DCP (direct current plasma) or EMP (electron microprobe) in 

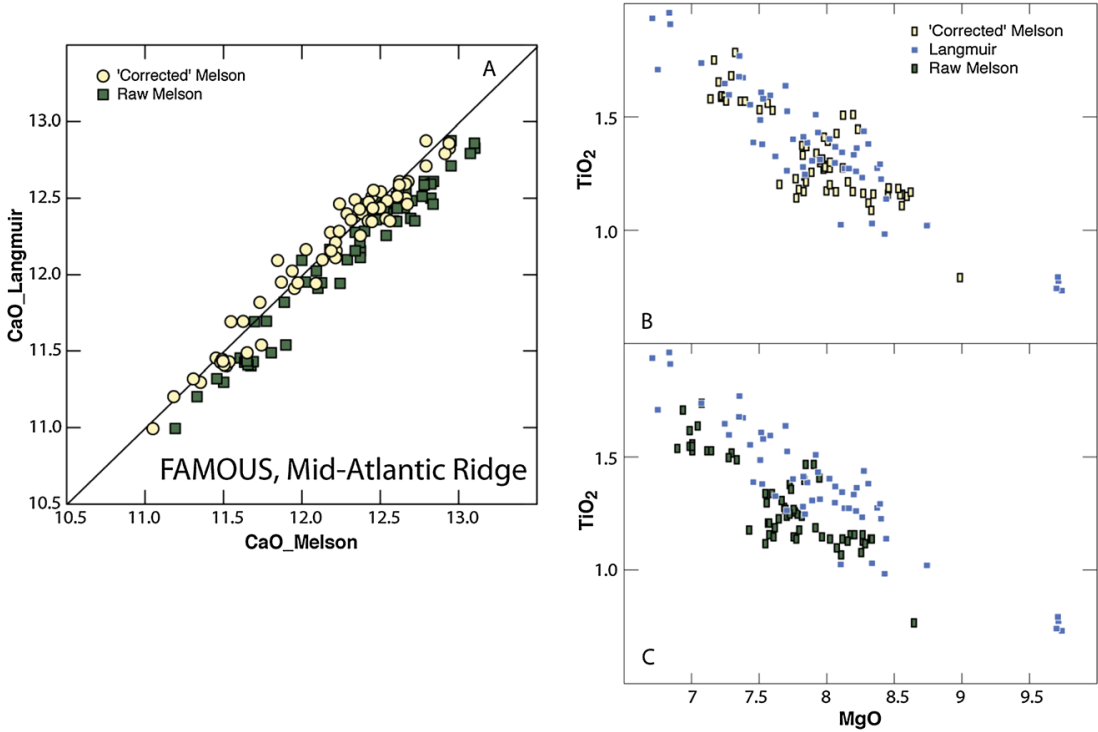

Figure 2. (A) Measurements of $\mathrm{CaO}$ (wt. \%) from both the Langmuir and Smithsonian laboratories on identical samples from the FAMOUS segment, with a 1:1 line for reference. (B, C) $\mathrm{TiO}_{2}$ (wt. \%) versus $\mathrm{MgO}$ (wt. \%) data from the Smithsonian and Langmuir laboratories on samples from a selected region of the Central Indian Ridge. The offset between laboratories is eliminated once proper interlaboratory bias corrections are applied. Without the application of such factors, apparent chemical differences in lavas caused simply by analytical procedures could be erroneously interpreted as true differences.

the Langmuir laboratories at Lamont-Doherty Earth Observatory and Harvard University. DCP protocol followed that described by Klein et al. [1991], and EMP techniques are described in Gale et al. [2011].

\subsection{Trace Elements and Isotopes}

[10] On 11 January 2011, we downloaded analyses from PetDB of 23,713 samples with at least one trace element measured. These data were then merged with extensive previously unpublished ICP-MS trace element data from Schilling (Kelley et al., 2013), Langmuir's laboratory, and two Ph.D. theses [Bézos, 2003; Standish, 2005], as well as analyses on Iceland samples from GeoROC. Some published trace element data sets absent in PetDB were also included, such as Sun et al. [2003, 2008]. Samples were then eliminated that either (a) were outside a segment polygon; (b) had a PetDB "Rock" classification of plutonic, metamorphic, or ultramafic; (c) did not have at least one of the following elements: $\mathrm{Ba}, \mathrm{Be}$, $\mathrm{Ce}, \mathrm{Co}, \mathrm{Cr}, \mathrm{Cs}, \mathrm{Cu}, \mathrm{Dy}, \mathrm{Er}, \mathrm{Eu}, \mathrm{Ga}, \mathrm{Gd}, \mathrm{Hf}, \mathrm{Ho}$, $\mathrm{La}, \mathrm{Li}, \mathrm{Lu}, \mathrm{Mn}, \mathrm{Mo}, \mathrm{Nb}, \mathrm{Nd}, \mathrm{Ni}, \mathrm{Pb}, \mathrm{Pr}, \mathrm{Rb}, \mathrm{Sc}$, Sm, Sn, Sr, Ta, Tb, Th, Ti, Tl, U, V, W, Y, Yb, Zn, and $\mathrm{Zr}$. The final trace element data compilation was then assembled as follows:

(1) Eliminating duplicates. Many of the previously unpublished Schilling (Kelley et al., 2013) and Langmuir ICP-MS data are on samples for which non-ICP-MS data have already been published in PetDB. To eliminate duplicates, all sample names were converted to the "PetDB" format (e.g., EN026 16D-1 in Schilling's file became END0026-016-001). In the case of duplicate Sample ID and material, if one analysis was by ICP-MS and the other was not, we eliminated the non-ICP-MS analysis. For identical samples with non-ICP-MS analyses, trace element data by all techniques were merged. In the case of multiple ICP-MS analyses on the same sample, Langmuir laboratory data were retained if available; otherwise the most recent data were kept.

[11] For 1516 samples (758 duplicate pairs), the same Sample ID had both whole rock and glass analyses. Where whole rock data were entirely redundant (i.e., every trace element analyzed in the whole rock was also analyzed in the glass), the glass analysis was used. Where there was incomplete overlap, the whole rock and glass data were merged if the trace elements in common had abundances within $5 \%$. Where the major or trace elements indicated differences too large to justify merging the analyses, only the highest-quality trace element analysis was used. Determination of quality was based on analytical method, using the protocol adopted by PetDB. 
[12] It is likely that there are interlaboratory biases in the trace element data. Unlike major elements, for which there are abundant data from different laboratories on the same samples, there is far less interlaboratory overlap for trace element analyses. An interlaboratory issue may be evident when comparing "analog elements" that should have constant ratios across a large range of source heterogeneity, melting, and differentiation processes. For example, using the large data sets from the Langmuir and Schilling laboratories, there is a clear discrepancy with the $\mathrm{Y} / \mathrm{Ho}$ ratio. Both laboratories find a constant ratio, but the values differ by $15 \%$, far outside of analytical uncertainty. On the other hand, the $\mathrm{Ba} / \mathrm{Rb}$ ratio is the same within error (see Supporting Information). Much work remains in order to make a full interlaboratory correction for trace element values.

(2) Merging major and trace elements. Major and trace element data then had to be merged using common Sample IDs and materials (glass or whole rock). Trace element data were removed for samples that had their major element analysis cut for being "out of the igneous range." Some samples have only major element or only trace element data. Of the 3971 samples in the final trace element database, 772 do not have a corresponding set of major elements.

(3) Selection for data quality. After the various filtering steps, 7078 samples remained with trace element data. Because of a large amount of scatter in this compilation, for subsequent analysis the database was limited to include only samples with trace elements measured by inductively coupled plasma mass spectrometry (ICP-MS), laser ablation ICP-MS (LA-ICP-MS), multi-collector ICP-MS (MC-ICP-MS), isotope dilution (ID), ICP atomic emission spectroscopy (ICPAES), and DCP. This selection for analytical method was possible because of the large amount of new trace element data we were able to include (e.g., data from the Gakkel Ridge, the Lau back-arc basin, the Afar region, and portions of the Central and Southwest Indian Ridges were not available for prior compilations, as well as substantially enhanced data sets from the East Pacific Rise and Mid-Atlantic Ridge). Of the 3971 trace element analyses in the final file, 1567 are previously unpublished.

[13] As a final filter for data quality, several "canonical" trace element ratios were checked to identify possible problem elements (excluding back-arc basins). If $\mathrm{Th} / \mathrm{U}<1.5, \mathrm{Nb} / \mathrm{U}<25$ or $>70, \mathrm{Ba} /$ $\mathrm{Rb}>18$ or $<7, \mathrm{Pr} / \mathrm{Pb}<1.6, \mathrm{Ce} / \mathrm{Pb}<11, \mathrm{Nb} / \mathrm{Th}>23$, $\mathrm{Li} / \mathrm{Yb}>2.5$ or $<1, \mathrm{Ta} / \mathrm{Th}>1.5, \mathrm{Nb} / \mathrm{Ta}<12.3$ or $>18.9, \mathrm{Ba} / \mathrm{Cs}<600$, or $\mathrm{Mo} / \mathrm{Ce}>0.05$, other ratios were evaluated to identify the problem element. For example, if $\mathrm{Th} / \mathrm{U}$ and $\mathrm{Nb} / \mathrm{U}$ were out of range and $\mathrm{Nb} / \mathrm{Th}$ was in range, $\mathrm{U}$ was eliminated. In the case where the $\mathrm{Ba} / \mathrm{Rb}$ ratio was out of range, both $\mathrm{Ba}$ and $\mathrm{Rb}$ were deleted. In out-of-range ratios involving $\mathrm{Pb}, \mathrm{Pb}$ was deleted as it is prone to contamination. The $\mathrm{Li} / \mathrm{Yb}$ ratio was used to search for erroneous $\mathrm{Li}$ values. For any samples with a $\mathrm{Mo} / \mathrm{Ce}$ ratio $>0.05$, the Mo value was deleted. Analog element pairs, such as Zr-Sm, Hf-Nd, and Y-Ho, were also examined to identify outliers. Each case of a deleted value is indicated in the Notes column of the tables in the Supporting Information.

[14] Late in the progress of this study, Jenner and $O$ 'Neill [2012] released 600 LA-ICP-MS trace element analyses on basaltic glasses from the Smithsonian collection. Of their 600 analyses, only 253 are located in our segment polygons; the database was augmented by their analyses $(n=116)$ for ridge segments that otherwise had no trace element data. The remaining analyses $(n=137)$ were not included, as there was already excellent coverage for those segments.

[15] Figure 3 shows the location of samples with trace element data in this study (red circles) compared with the location of samples with trace element data in the recent $A M$ [2010] study (yellow circles). While the new data set is more inclusive almost everywhere, it greatly improves coverage of the Reykanes and Kolbeinsey sections of the Mid-Atlantic Ridge, the Central Indian Ridge, Pacific-Antarctic Ridge, Afar, Gakkel Ridge, and back-arc basins, and it excludes off-axis samples.

[16] For samples in the trace element database, existing $\mathrm{Sr}, \mathrm{Nd}, \mathrm{Pb}$, and $\mathrm{Hf}$ isotopic data were added, including both published data and previously unpublished values from Schilling's laboratory (Kelley et al., 2013). A quality check to remove obvious typos and outliers led to elimination of very few data.

\section{Calculation of Average Compositions}

[17] Calculation of an "average" composition of ocean ridge basalts is complicated by a number of factors including uneven sampling, skewed distributions, and whether or not to include hot-spot-influenced or 


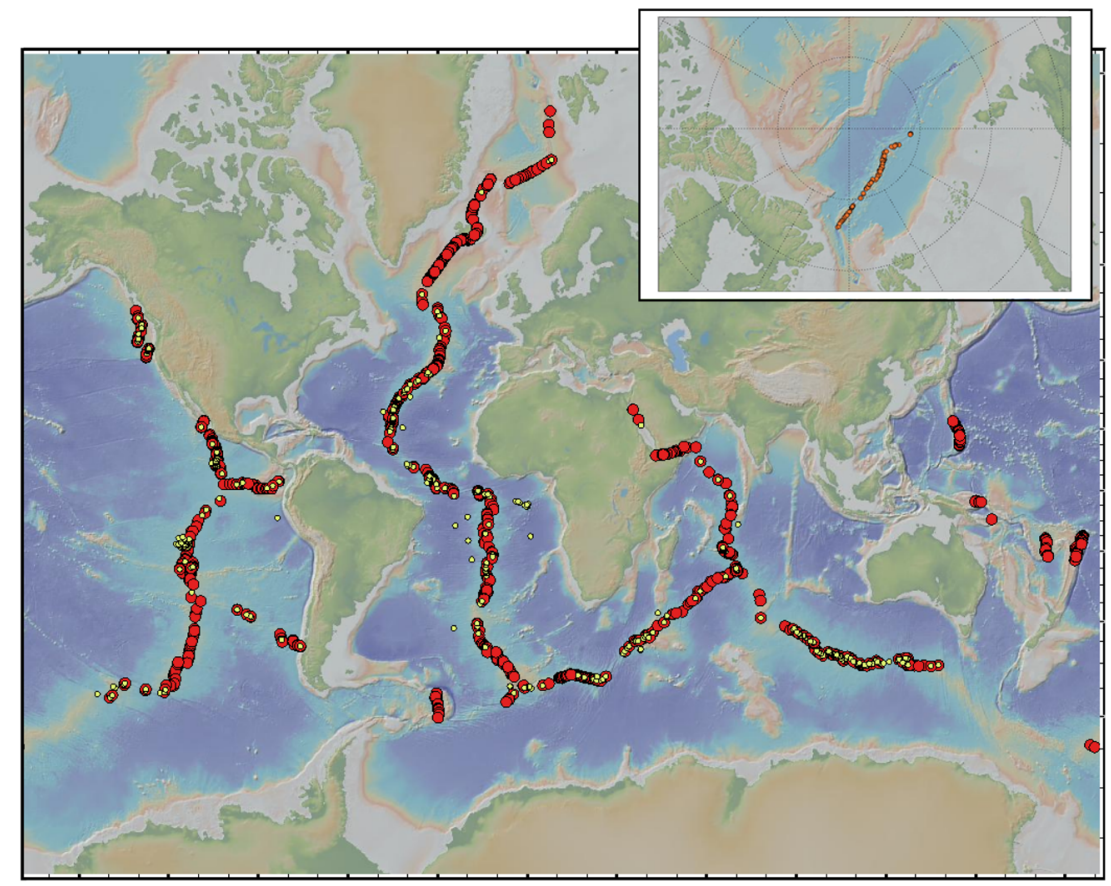

Figure 3. Comparison of the locations of samples with trace element data used in this study (larger red circles) to those used in Arevalo and McDonough [2010] (smaller yellow circles). Inset shows the location of samples from the Gakkel Ridge in the Arctic. The new data set greatly improves coverage of the Reykjanes and Kolbeinsey sections of the MidAtlantic Ridge, the Central Indian Ridge, Pacific-Antarctic Ridge, Afar, Gakkel Ridge, and back-arc basins, and it excludes off-axis samples. Bathymetry from GeoMapApp [Ryan et al., 2009].

back-arc basalts. In the following sections, we address the various challenges that are associated with determining an average composition.

\subsection{Uneven Sampling}

[18] Certain regions of the ridge have been preferentially sampled, with obvious implications for a globally representative average composition. We address this issue by using segment average values. Even a segment average, however, can be nonrepresentative when one location has dozens of analyses, often from a flow of uniform composition, and another location has only a single analysis. Major element segment averages, therefore, are based on location average values within a segment. For the best-sampled case of the $9^{\circ} \mathrm{N}$ segment of the EPR (EPRR29), 641 unique sample locations were used to arrive at a segment mean. For certain other segments, a single sample location was used. Using location and segment means greatly reduces the bias introduced by uneven sampling.

[19] For trace elements, there are additional challenges. While multiple analyses of samples from the same location are much less common, there is the problem of incomplete trace element data, such as Ba data on six samples and Cs data on only three of those samples. If the three samples lacking Cs data were chemically distinct, the mean Cs would not be as representative as the mean $\mathrm{Ba}$, possibly resulting in a $\mathrm{Ba} / \mathrm{Cs}$ ratio for that segment that deviates from that in the natural samples. This concern is reduced by the use of mostly ICP-MS data in our compilation, for which chemical analyses are much more complete, but data gaps do exist.

[20] One option for dealing with such data gaps is to estimate the missing data using canonical relationships between analog elements and to then calculate a segment average that includes the estimated values. This option may result in more reasonable trace element ratios for each segment, but it requires the creation of synthetic data and assumptions about analog elements. A second option is to only consider samples with complete trace element data. However, this requirement would eliminate $82 \%$ of the samples with trace element analyses in our database, severely restricting global data coverage. A third option, and the one adopted by this study, is to accept the data gaps and calculate a trace element segment average using all available samples that contain data for a particular element. The appeal of this approach is 
that no synthetic data are created and no assumptions are required. Furthermore, we demonstrate below that the data gaps do not strongly influence the global and regional mean compositions. It must be noted, however, that a consequence of this third option is that trace element ratios for an individual segment may be compromised.

[21] For isotopes, the isotopic ratio of each sample must be weighted by its elemental concentration in order to arrive at meaningful isotopic ratios for each segment. For example,

$$
\frac{{ }^{143} \mathrm{Nd}}{{ }^{144} \mathrm{Nd}_{M}}=\frac{\sum_{i=1}^{N} \frac{{ }^{143} \mathrm{Nd}}{144 \mathrm{Nd}_{i}} * \mathrm{Nd}_{i}}{\sum_{i=1}^{N} \mathrm{Nd}_{i}},
$$

where ${ }^{143} \mathrm{Nd} /{ }^{144} \mathrm{Nd}_{\mathrm{M}}$ is the mean ${ }^{143} \mathrm{Nd} /{ }^{144} \mathrm{Nd}$ of the segment, ${ }^{143} \mathrm{Nd} /{ }^{144} \mathrm{Nd}_{\mathrm{i}}$ is the ${ }^{143} \mathrm{Nd} /{ }^{144} \mathrm{Nd}$ of the ith sample from the segment, $\mathrm{Nd}_{\mathrm{i}}$ is the concentration of the ith sample, and the sum is over the N samples from the segment. Segment average values for major elements $(n=465)$, trace elements $(n=455)$, and isotopic ratios $(n=308)$ are provided in the Supporting Information.

\subsection{Skewed Distributions and Arithmetic Versus Log-Normal Means}

[22] The concentrations of highly incompatible trace elements such as $\mathrm{Ba}, \mathrm{Th}, \mathrm{U}$, and $\mathrm{Nb}$ in ocean ridge basalts can span many orders of magnitude and have positively skewed distributions, a characteristic shared by the segment means (Figure 4a). Moderately incompatible elements are less skewed but still not Gaussian (Figure 4b).

[23] Positively skewed distributions can be converted to Gaussian distributions by taking the logarithm of the variable [e.g., see $A M, 2010$ ], producing a "log-normal" distribution. The arithmetic mean (the mean) and the mean of the log-normal distribution (geometric mean) differ (Figure 4a). The log-normal mean approximates the median value of the distribution and is less influenced by the few high concentrations. The arithmetic mean gives the actual composition of the global ocean crust, answering the question, "What is the concentration of a given element in the ocean crust reservoir?" The log-normal mean addresses the different question, "What is the typical concentration of a given element in ridge basalts?," providing the most common basalt composition within the entire sample population.

\subsubsection{Calculation of the Arithmetic Mean}

[24] The mean composition was calculated using the segment mean values weighted by both segment length and spreading rate. The contribution of a long, fast-spreading ridge segment to the total ocean crust budget per unit time is larger than the contribution of a short, ultraslow spreading segment. The ability to weight by spreading rate and length is another utility of the "segment means" approach, since such weighting is impossible with individual samples absent segment information.

[25] The mean for isotopic ratios requires an additional step. For the global averages of isotopic ratios, each segment must be weighted by concentration in addition to spreading rate and length. A difficulty is that often the average segment concentration of, for example, $\mathrm{Nd}$ is calculated from many more samples than have measured $\mathrm{Nd}$ isotopic ratios. If the average $\mathrm{Nd}$ concentration of the samples with measured isotopes differs from the average $\mathrm{Nd}$ concentration of all the samples, then weighting using the segment concentrations may be invalid. This turns out not to be a problem as there is no difference between (1) weighting the segment isotopic ratio by the segment element concentration (and spreading rate and length) $\left({ }^{143} \mathrm{Nd} /{ }^{144} \mathrm{Nd}_{\mathrm{M}}=0.513074\right)$ and (2) weighting the segment isotopic ratio by the average element concentration of only those samples with measured isotopic ratios (and spreading rate and length) $\left({ }^{143} \mathrm{Nd} /{ }^{144} \mathrm{Nd}_{\mathrm{M}}=0.513073\right)$. The mean isotopic ratios reported in this paper are calculated using the first method.

\subsubsection{Calculation of the Log-Normal Mean}

[26] Spreading rate should not be a factor in calculating the typical composition erupted along the length of the ridge system. (Spreading rate would come into play to estimate the typical basalt composition of the entire ocean basin.) Segment length still matters, however, as samples from longer segments are more frequently encountered than those from shorter segments. Therefore, the lognormal means include weighting by segment length but not spreading rate.

[27] In order to estimate a $95 \%$ confidence interval on the distribution of a particular element, we converted the trace element content of each segment of ridge into the trace element content of each kilometer of ridge (for which data exist) using the segment means and segment length. Using these data, the 

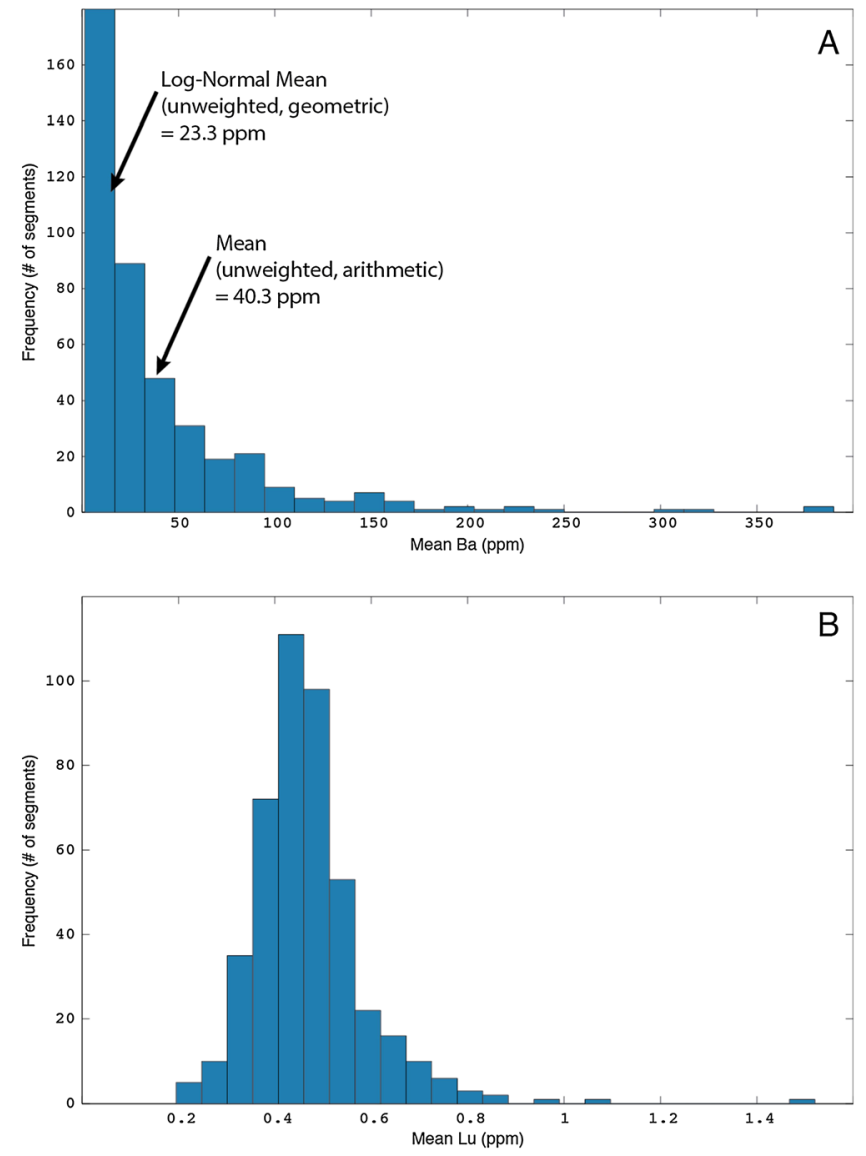

Figure 4. Comparison of the frequency distribution of the mean concentration of $\mathrm{Ba}(\mathrm{A})$, a highly incompatible element, to that of moderately incompatible element $\mathrm{Lu}(\mathrm{B})$ in global ridge segments. Note that both distributions are positively skewed, but the skewness is more pronounced in highly incompatible elements because their concentrations span many more orders of magnitude (e.g., factor of 260 change in Ba versus a factor of 8 change in $\mathrm{Lu}$ ). The non-Gaussian distribution of the segment-average trace element data results in two distinct means: the log-normal (geometric) and true (arithmetic) mean, indicated in Figure 4a, both of which provide insights on the composition of ridge basalts. See text for more details.

log-normal mean and $2 \sigma$ standard deviation (95\% confidence interval) were determined and are reported in Tables 1 and 2.

\subsection{Physical Interpretation of Standard Deviations}

[28] Standard deviations for skewed distributions cannot be used to estimate confidence intervals. For example, the mean $\pm 2 \sigma$ standard deviations for $\mathrm{Ba}$ reported by $\mathrm{Su}$ [2002] (36.2 \pm 84.8$)$ and $A M$ [2010] (34.3 \pm 98$)$ are clearly non-physical, implying negative concentrations. To estimate a confidence interval on the data distribution, the standard deviation of the log-normal distribution (which is Gaussian) can be used instead, as discussed in the preceding section.

[29] A more important parameter is the confidence interval on the mean. For example, a key question is whether or not the silicate Earth is chondritic [e.g., Jackson and Carlson, 2012, and references therein]. The mean composition of the ocean crust can provide important constraints on this question but only if the uncertainty on the mean is well determined. For this, the standard deviation of the mean (standard deviation $/ \sqrt{n}$ ) is applicable, even for skewed distributions [e.g., Devore and Peck, 2005].

[30] An approach to the standard deviation of the mean that provides flexible use of weighting factors, however, is the statistical bootstrapping technique. Bootstrapping re-samples the entire population randomly, allowing some data (segments) to be counted more than once and some not at all. For example, for 428 segments with $\mathrm{Ba}$ data, bootstrapping randomly selects a new combination of 428 segments with replacement (allowing repeats). Each random selection of 428 segments is counted as one trial, and the mean of those randomly picked segments is 
Table 1. The Composition of ALL MORB ${ }^{\mathrm{a}}$

\begin{tabular}{|c|c|c|c|c|c|c|c|}
\hline & $\mathrm{n}$ & $\begin{array}{l}\text { ALL MORB } \\
\text { Mean }^{b}\end{array}$ & $\pm(95 \%$ conf $)$ & $\begin{array}{c}\text { ALL MORB } \\
\text { Log-Normal Mean }\end{array}$ & $\pm(95 \%$ conf $)$ & Upper Bound & Lower Bound \\
\hline $\mathrm{MgO}$ & 430 & 7.58 & 0.12 & 7.69 & 0.08 & 9.04 & 6.21 \\
\hline $\mathrm{SiO}_{2}$ & 430 & 50.47 & 0.08 & 50.41 & 0.08 & 51.75 & 49.22 \\
\hline $\mathrm{FeO}$ & 430 & 10.43 & 0.21 & 10.07 & 0.14 & 13.48 & 8.12 \\
\hline $\mathrm{CaO}$ & 430 & 11.39 & 0.09 & 11.35 & 0.07 & 12.49 & 10.15 \\
\hline $\mathrm{Na}_{2} \mathrm{O}$ & 430 & 2.79 & 0.03 & 2.76 & 0.04 & 3.69 & 2.06 \\
\hline $\mathrm{Al}_{2} \mathrm{O}_{3}$ & 430 & 14.70 & 0.12 & 14.95 & 0.10 & 16.74 & 13.25 \\
\hline $\mathrm{TiO}_{2}$ & 430 & 1.68 & 0.05 & 1.54 & 0.03 & 2.32 & 1.06 \\
\hline $\mathrm{K}_{2} \mathrm{O}$ & 430 & 0.160 & 0.014 & 0.144 & 0.011 & 0.558 & 0.045 \\
\hline $\mathrm{P}_{2} \mathrm{O}_{5}$ & 409 & 0.184 & 0.012 & 0.169 & 0.008 & 0.400 & 0.082 \\
\hline $\mathrm{MnO}$ & 379 & 0.184 & 0.005 & 0.173 & 0.004 & 0.231 & 0.105 \\
\hline $\mathrm{Ba}$ & 392 & 29.2 & 3.8 & 23.1 & 2.7 & 160.3 & 3.9 \\
\hline $\mathrm{Be}$ & 139 & 0.76 & 0.05 & 0.64 & 0.05 & 1.22 & 0.25 \\
\hline $\mathrm{Ce}$ & 410 & 14.86 & 1.26 & 12.99 & 0.70 & 33.18 & 5.09 \\
\hline Co & 350 & 43.0 & 0.7 & 42.9 & 0.5 & 53.0 & 35.9 \\
\hline $\mathrm{Cr}$ & 369 & 249 & 12 & 251 & 11 & 406 & 81 \\
\hline Cs & 272 & 0.034 & 0.006 & 0.029 & 0.004 & 0.175 & 0.006 \\
\hline $\mathrm{Cu}$ & 357 & 74 & 2 & 75 & 2 & 122 & 57 \\
\hline Dy & 411 & 6.08 & 0.30 & 5.43 & 0.17 & 8.83 & 3.66 \\
\hline $\mathrm{Er}$ & 410 & 3.79 & 0.17 & 3.37 & 0.10 & 5.71 & 2.28 \\
\hline $\mathrm{Eu}$ & 411 & 1.36 & 0.05 & 1.25 & 0.03 & 2.02 & 0.81 \\
\hline $\mathrm{Ga}$ & 300 & 17.5 & 0.2 & 17.1 & 0.2 & 20.0 & 14.6 \\
\hline $\mathrm{Gd}$ & 386 & 4.99 & 0.23 & 4.51 & 0.14 & 7.56 & 2.98 \\
\hline $\mathrm{Hf}$ & 398 & 2.79 & 0.15 & 2.44 & 0.10 & 4.51 & 1.26 \\
\hline Ho & 404 & 1.28 & 0.05 & 1.16 & 0.03 & 1.85 & 0.78 \\
\hline $\mathrm{La}$ & 412 & 5.21 & 0.53 & 4.51 & 0.30 & 16.32 & 1.43 \\
\hline $\mathrm{Li}$ & 255 & 6.5 & 0.3 & 6.0 & 0.2 & 9.1 & 3.7 \\
\hline $\mathrm{Lu}$ & 410 & 0.53 & 0.02 & 0.48 & 0.01 & 0.83 & 0.32 \\
\hline Mo & 185 & 0.46 & 0.05 & 0.41 & 0.04 & 1.24 & 0.16 \\
\hline $\mathrm{Nb}$ & 402 & 5.24 & 0.59 & 4.11 & 0.38 & 24.50 & 1.01 \\
\hline $\mathrm{Nd}$ & 418 & 12.03 & 0.78 & 10.81 & 0.45 & 22.55 & 5.40 \\
\hline $\mathrm{Ni}$ & 365 & 92 & 5 & 97 & 4 & 183 & 44 \\
\hline $\mathrm{Pb}$ & 370 & 0.57 & 0.03 & 0.53 & 0.03 & 1.31 & 0.20 \\
\hline $\operatorname{Pr}$ & 390 & 2.24 & 0.12 & 2.05 & 0.09 & 4.15 & 0.92 \\
\hline $\mathrm{Rb}$ & 380 & 2.88 & 0.44 & 2.15 & 0.27 & 13.87 & 0.37 \\
\hline $\mathrm{Sc}$ & 338 & 39.8 & 0.8 & 38.8 & 0.6 & 49.2 & 29.5 \\
\hline $\mathrm{Sm}$ & 417 & 3.82 & 0.15 & 3.49 & 0.10 & 6.17 & 2.06 \\
\hline $\mathrm{Sn}$ & 200 & 0.92 & 0.06 & 0.79 & 0.05 & 1.63 & 0.28 \\
\hline $\mathrm{Sr}$ & 413 & 129 & 4 & 129 & 5 & 246 & 70 \\
\hline $\mathrm{Ta}$ & 352 & 0.34 & 0.04 & 0.27 & 0.03 & 1.44 & 0.07 \\
\hline $\mathrm{Tb}$ & 397 & 0.90 & 0.04 & 0.82 & 0.02 & 1.31 & 0.53 \\
\hline Th & 395 & 0.404 & 0.081 & 0.292 & 0.033 & 2.135 & 0.059 \\
\hline $\mathrm{Tl}$ & 200 & 0.020 & 0.001 & 0.019 & 0.001 & 0.041 & 0.006 \\
\hline $\mathrm{U}$ & 374 & 0.119 & 0.013 & 0.095 & 0.009 & 0.495 & 0.022 \\
\hline V & 337 & 309 & 13 & 287 & 7 & 396 & 194 \\
\hline W & 209 & 0.12 & 0.02 & 0.10 & 0.01 & 0.40 & 0.01 \\
\hline $\mathrm{Y}$ & 410 & 36.8 & 1.9 & 32.6 & 1.0 & 53.6 & 21.5 \\
\hline $\mathrm{Yb}$ & 411 & 3.63 & 0.18 & 3.23 & 0.10 & 5.80 & 2.15 \\
\hline $\mathrm{Zn}$ & 338 & 91.3 & 3.1 & 86.6 & 1.9 & 119.5 & 59.9 \\
\hline $\mathrm{Zr}$ & 412 & 116.9 & 8.4 & 100.7 & 4.4 & 220.0 & 49.9 \\
\hline${ }^{87} \mathrm{Sr} /{ }^{86} \mathrm{Sr}$ & 272 & 0.702819 & 0.000067 & & & & \\
\hline${ }^{143} \mathrm{Nd} /{ }^{144} \mathrm{Nd}$ & 272 & 0.513074 & 0.000017 & & & & \\
\hline${ }^{206} \mathrm{~Pb} /{ }^{204} \mathrm{~Pb}$ & 245 & 18.412 & 0.090 & & & & \\
\hline${ }^{207} \mathrm{~Pb} /{ }^{204} \mathrm{~Pb}$ & 245 & 15.515 & 0.010 & & & & \\
\hline${ }^{208} \mathrm{~Pb} /{ }^{204} \mathrm{~Pb}$ & 245 & 38.100 & 0.091 & & & & \\
\hline${ }^{176} \mathrm{Hf} /{ }^{177} \mathrm{Hf}$ & 138 & 0.283 & 0.000 & & & & \\
\hline $\mathrm{Sm} / \mathrm{Nd}$ & 416 & 0.325 & 0.005 & & & & \\
\hline $\mathrm{Zr} / \mathrm{Hf}$ & 398 & 40.64 & 0.95 & & & & \\
\hline $\mathrm{Ba} / \mathrm{Th}$ & 376 & 71.93 & 8.32 & & & & \\
\hline $\mathrm{Nb} / \mathrm{U}$ & 366 & 44.37 & 1.99 & & & & \\
\hline
\end{tabular}


Table 1. (continued)

\begin{tabular}{|c|c|c|c|c|c|c|c|}
\hline & $\mathrm{n}$ & $\begin{array}{l}\text { ALL MORB } \\
\text { Mean }^{b}\end{array}$ & $\pm(95 \%$ conf $)$ & $\begin{array}{c}\text { ALL MORB } \\
\text { Log-Normal Mean }^{c}\end{array}$ & $\pm(95 \%$ conf $)$ & Upper Bound & Lower Bound \\
\hline $\mathrm{Ce} / \mathrm{Pb}$ & 364 & 24.85 & 1.07 & & & & \\
\hline $\mathrm{Nb} / \mathrm{Ta}$ & 352 & 15.19 & 0.62 & & & & \\
\hline $\mathrm{Th} / \mathrm{U}$ & 372 & 3.16 & 0.11 & & & & \\
\hline $\mathrm{Ba} / \mathrm{Rb}$ & 376 & 10.87 & 0.52 & & & & \\
\hline $\mathrm{Ba} / \mathrm{Cs}$ & 265 & 876 & 35 & & & & \\
\hline $\mathrm{Rb} / \mathrm{Cs}$ & 266 & 77.56 & 3.08 & & & & \\
\hline K/U & 347 & 12344 & 812 & & & & \\
\hline Y/Ho & 393 & 28.09 & 0.44 & & & & \\
\hline $\mathrm{Zr} / \mathrm{Sm}$ & 410 & 29.83 & 0.66 & & & & \\
\hline $\mathrm{Hf} / \mathrm{Nd}$ & 398 & 0.237 & 0.006 & & & & \\
\hline $\mathrm{Y} / \mathrm{Yb}$ & 408 & 10.12 & 0.11 & & & & \\
\hline
\end{tabular}

\footnotetext{
${ }^{\text {a }}$ This mean composition is calculated using all possible ridge segments except back-arc spreading centers. Both the arithmetic and log-normal means are provided with confidence intervals; the arithmetic mean (bold font) is our preferred ALL MORB composition. The upper and lower bounds bracket the composition of $95 \%$ of the sampled ridge length. Column " $n$ " indicates the number of segments used to determine the global mean compositions. PARR2 was omitted when calculating the global $\mathrm{Sm} / \mathrm{Nd}, \mathrm{Ce} / \mathrm{Pb}, \mathrm{Zr} / \mathrm{Sm}$, and $\mathrm{Y} / \mathrm{Ho}$ ratios. CHIL27 was omitted during the calculation of the Rb/Cs ratio. MARR251, EPRR30, FIJI3, FIJI6, SWIR 66, GALA15 and EPRR22 were omitted during calculation of global the $\mathrm{Y} / \mathrm{Ho}$ ratio. Isotopic ratios have been weighted by concentration in addition to spreading rate and length (see text for details).

${ }^{b}$ Mean weighted by spreading rate and length.

${ }^{c}$ Log-normal mean, weighted by length only.
}

calculated. Bootstrapping makes the assumption that the distribution of the true population is reasonably approximated by the distribution of the subsample (i.e., that the histogram shape of the 428 segments with data is similar to that of all 771 segments). It does not matter whether the distribution is Gaussian or not. Given that the database includes ridge segments from the full range of spreading rates and ridge depths, from plume-influenced and nonplume-influenced regions, and from back-arc spreading centers, it is reasonable to assume that the distribution of the existing subsample approximates that of the true population.

[31] For the assessment of errors on the mean and log-normal means, 1000 bootstrapping trials were carried out for each element. The distribution of those means then quantifies the uncertainty on the mean values (Figure 5). Tables 1 and 2 provide the average compositions and $95 \%$ confidence intervals. This permits statements such as the following: (1) the mean composition of $\mathrm{Ba}$ in the ocean crust is $29.2 \mathrm{ppm} \pm 3.8$, (2) the typical value of $\mathrm{Ba}$ in ocean crust is $23.1 \mathrm{ppm} \pm 2.7$, and (3) $95 \%$ of ocean crust segment means have between 3.9 and $160.3 \mathrm{ppm} \mathrm{Ba}$. Note that the $95 \%$ envelope in (3) is highly asymmetric around the mean.

\subsection{Trace Element Data Gaps and Trace Element Ratios}

[32] Trace element data gaps among segments could influence mean values. For example, 454 segments have $\mathrm{Nd}$ data, while only 154 segments have Be data. If there were 454 segments with Be data, would the reported mean change significantly? To explore this issue, the variations in the means for 18 trace elements with data from more than 427 segments were calculated by randomly selecting data from 154 segments. These data were then bootstrapped to determine the errors on the mean. Not surprisingly, the uncertainties on the means for the elements increase when bootstrapping from a smaller sample size. For all 18 elements, however, the original mean (calculated from $400+$ segments) was captured within the mean $\pm 2 \sigma$ calculated by bootstrapping with only 154 segments. Therefore, while the reported mean for Be is less well determined, it is likely that the actual mean is captured within the $95 \%$ confidence interval.

[33] Note that because of the differences in data coverage between $\mathrm{Be}$ and $\mathrm{Nd}$, the $\mathrm{Be} / \mathrm{Nd}$ ratio calculated from the mean concentrations is not necessarily the $\mathrm{Be} / \mathrm{Nd}$ ratio seen in natural lavas. Calculating ratios using segment averages requires propagating the errors on the individual elements to be sure to encompass the true ratio, resulting in large uncertainties. A more careful treatment of ratios, described below, can narrow these errors considerably.

[34] To determine more accurate trace element ratios, only segments that have data for both elements of the ratio were used. For example, 302 segments have both $\mathrm{Rb}$ and $\mathrm{Cs}$ data-fewer than the number 


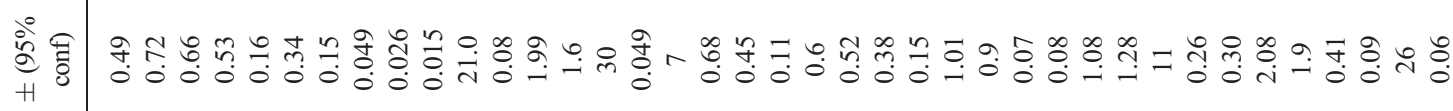

舟营

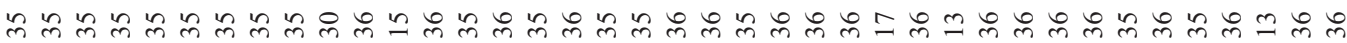

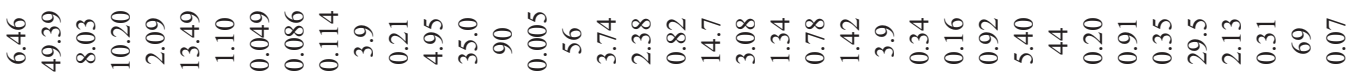

空言

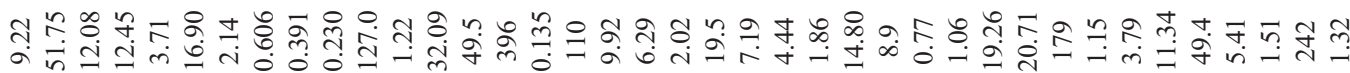

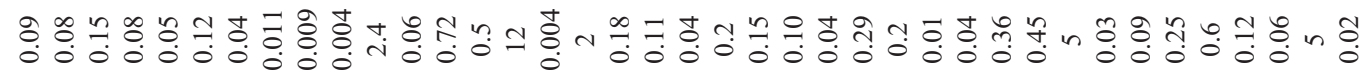

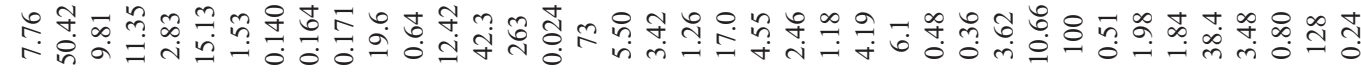

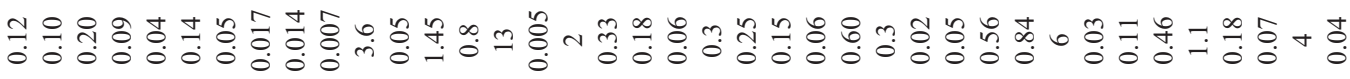

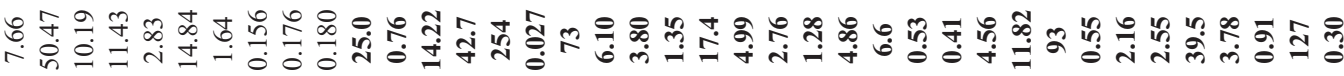

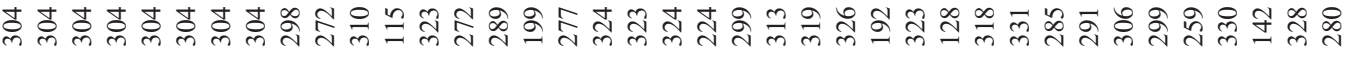

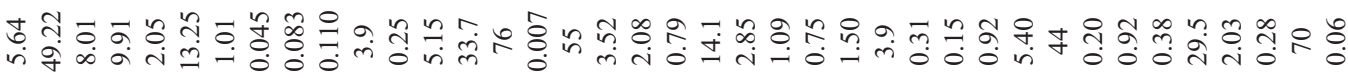

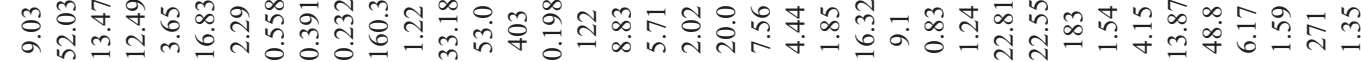

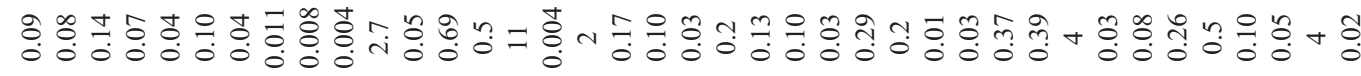

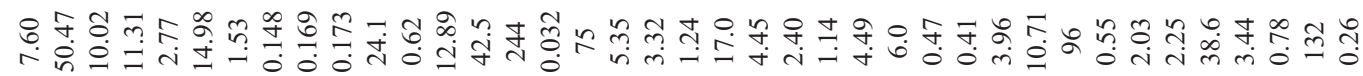

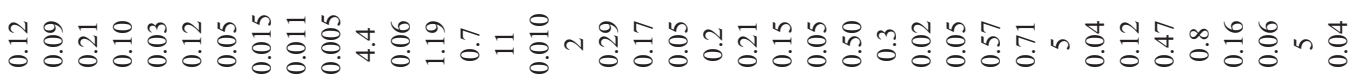

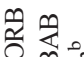

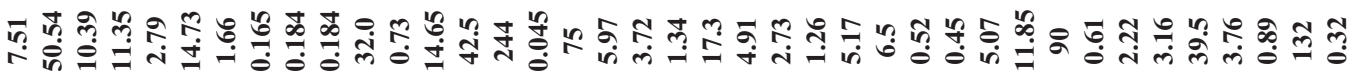

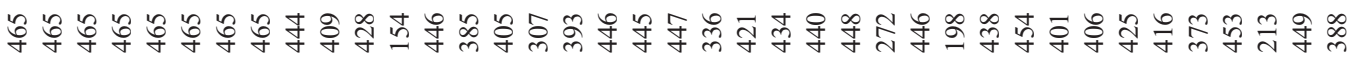




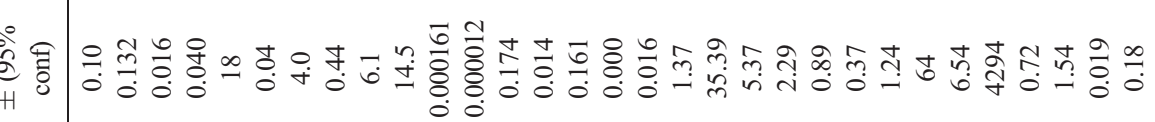

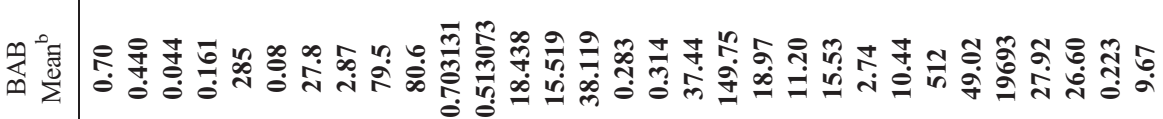

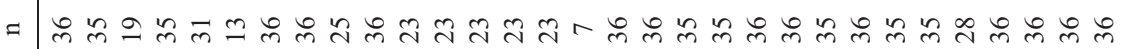

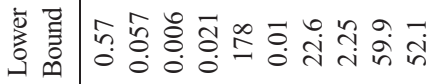

亏े

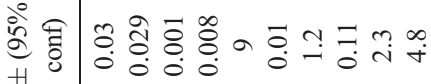

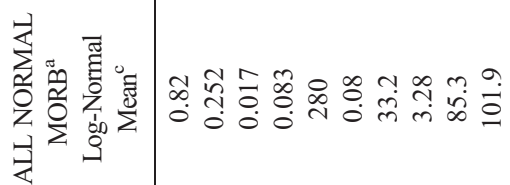

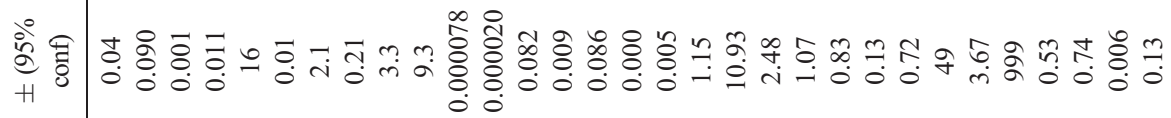

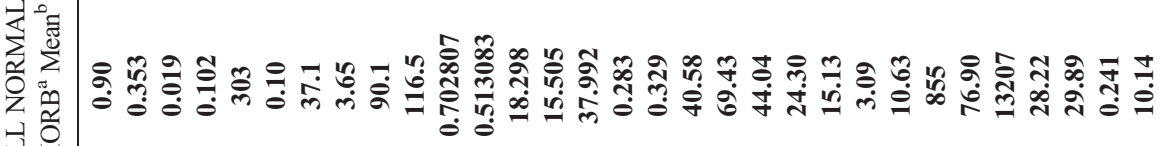

安完

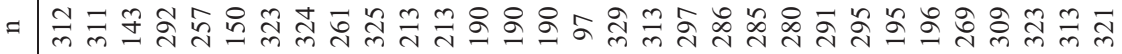

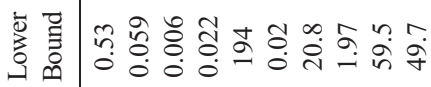

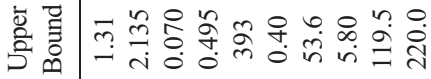

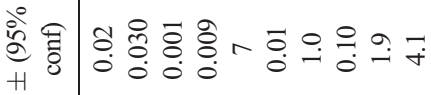

चै 要

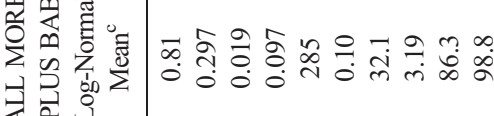

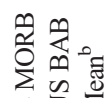

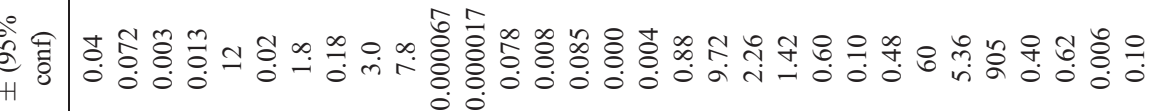

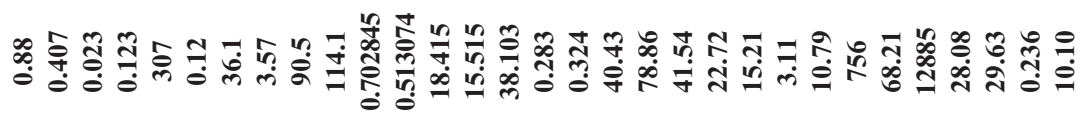

当家

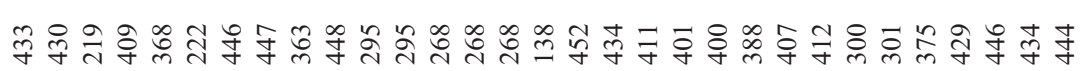


of segments with $\mathrm{Rb}$ (416) and Cs (307). To calculate the $\mathrm{Rb} / \mathrm{Cs}$ ratio, the 302 segments were bootstrapped to calculate the mean $\mathrm{Rb}$ and mean $\mathrm{Cs}$, and the means divided to determine the ratio. The mean and uncertainty of the 1000 bootstrapped $\mathrm{Rb} / \mathrm{Cs}$ ratios provide confidence intervals for that trace element ratio. In the case of $\mathrm{Rb} / \mathrm{Cs}$, the $\%$ error on the ratio is less than the \% error on the mean Cs concentration. This holds true for many other calculated ratios. The fact that the error is smaller on the ratio than on the concentration demonstrates that accurate errors on the ratio cannot be propagated directly from errors on the individual trace element concentrations. The number of segments used in the ratio calculations is provided with each reported ratio in Tables 1 and 2 .

\section{A Proposed New Nomenclature for MORB}

[35] A heritage for naming MORB compositions derives from early work that hypothesized a uniform, depleted upper mantle punctuated by enriched hot spots, with transitional zones in between [e.g. Schilling and Winchester, 1966; Schilling, 1975]. Within this framework, N-MORB ("Normal MORB") were depleted MORB taken to represent the uniform, depleted upper mantle and occurring at mean depths of some $2600 \mathrm{~m}$, E-MORB were enriched MORB associated with hot spots and their positive bathymetric anomalies, and T-MORB were transitional MORB occurring on hot spot margins [e.g., Sun et al., 1979]. This original concept remains in the way many think about ocean ridges and the upper mantle, and is entrenched in the literature. It is also reflected in the pervasive attitude that enriched compositions should be excluded when considering variations in the "normal" portion of the MORB population.

[36] It is now evident that this view of MORB does not accurately reflect reality. Relatively enriched MORB are not uncommon far from hot spots, and some hot spot margins are quite depleted. The more comprehensive view of MORB in this study leads us to suggest a new vocabulary for MORB compositions that more accurately reflects the global data distribution.

[37] We suggest the term "ALL MORB" as the mean composition of the basaltic portion of the ocean crust excluding back-arc basins. This mean, which represents the concentration of elements in the zero age ocean crust reservoir, is also the best proxy from which to infer the total composition of the upper mantle. The preferred ALL MORB composition is calculated with plumes and without back arcs, since plumes contribute to the upper mantle composition, and back arcs may simply be a "pass through" of subduction zone components. To accommodate the diverse points of view of others who may prefer a different averaging choice, we also present values calculated with and without back-arc and plume-influenced segments.

[38] We suggest that the term "N-MORB" should accurately reflect the word "normal" and be used to refer to the most likely basalt composition encountered along the global ridge system distant from hot spots. Such a composition is represented by the lognormal mean of segments more than $500 \mathrm{~km}$ from plumes (332/419 segments, excluding back arcs). (Note that "N-MORB" is distinguished from the ALL NORMAL MORB average by being a log-normal rather than arithmetic mean.) This definition is the largest change from current usage. The term "N-MORB" has traditionally been used for a highly depleted composition, considered to be "normal." As shown in this work, normal MORB is not highly depleted, so the association between the words "normal" and "highly depleted" needs to be broken.

[39] A term is also needed for the most highly depleted MORB ("D-MORB"), though they are not representative of the ocean crust or upper mantle composition, nor are they the most common MORB encountered away from hot spots. The presented D-MORB composition is the log-normal mean of segments with $\mathrm{La} / \mathrm{Sm}_{\mathrm{N}}<0.8$ (normalized to primitive mantle) [Sun and McDonough, 1989], excluding back arcs (225/419 segments).

[40] It is also useful to have a clear definition of "E-MORB." We define it as the log-normal mean of segments with $\mathrm{La} / \mathrm{Sm}_{\mathrm{N}}>1.5$ (38/419 segments, excluding back arcs).

\section{Presentation of MORB Average Compositions}

[41] This section presents the new "ALL MORB," N-MORB, D-MORB, and E-MORB compositions and compares them to previous literature values.

\subsection{The "ALL MORB" Average}

[42] The "ALL MORB" composition, our preferred composition for the ocean crust reservoir, is presented in bold in Table 1. This average includes plumes and excludes back arcs. Back arcs are an 


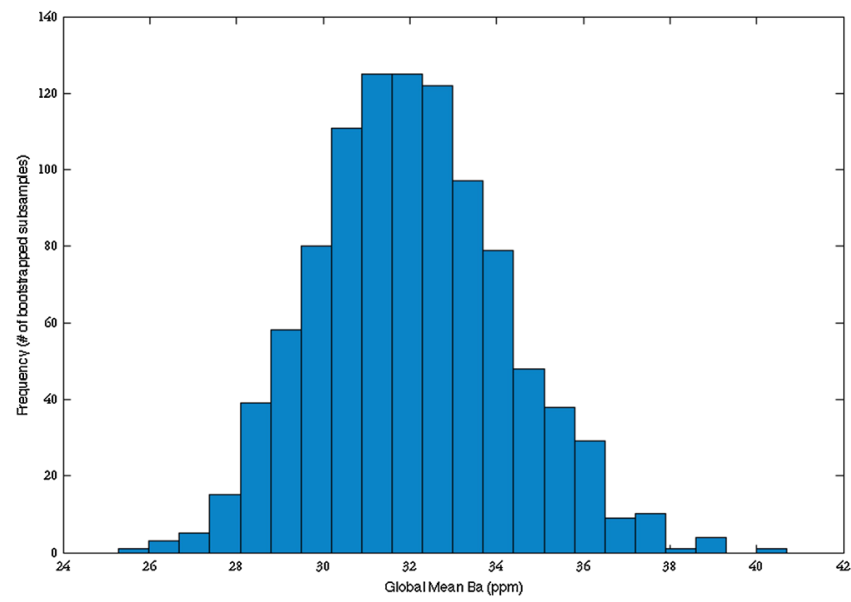

Figure 5. The distribution of the global mean Ba content for 1000 bootstrapped trials. Each bootstrapped trial is the mean $\mathrm{Ba}$ of a random resample of the initial global segment population, with replacement. The distribution of mean values enables the calculation of a $95 \%$ confidence interval on the mean compositions reported in this paper. Note that the distribution of means is Gaussian, even though the initial population is decidedly non-Gaussian (Figure 4a). The global mean shown here of $32 \pm 4.4$ ppm differs from the ALL MORB composition in Table 2 because ALL MORB excludes BAB segments.

important component of the ocean ridge system, but the distinctive geochemical signature they contain [e.g., Langmuir et al., 2006, and references therein] directly reflects proximity to a fluid flux from the slab, limited to $\sim<100 \mathrm{~km}$ from the volcanic front of the arc. This fluid flux does not seem to contribute to the overall upper mantle composition, as no heterogeneity far from a subduction zone inherits this signature. In contrast, mantle plumes are solid-state additions to the upper mantle, can have effects that extend over $1000 \mathrm{~km}$ or more, and do mix into the upper mantle and contribute to its overall composition.

[43] Table 2 provides several alternative compositions: "ALL MORB PLUS BAB," which includes all segments utilized by "ALL MORB" plus backarc spreading centers, and "ALL NORMAL MORB," which excludes both back-arc basins and any segment within $500 \mathrm{~km}$ of the hot spots identified by Courtillot et al. [2003]. These averages are remarkably similar to one another. For trace elements more compatible than $\mathrm{Pr}$, there is no difference between the three different compositions, indicating that the average concentration of the moderately incompatible elements in ocean crust can be estimated with great confidence. For elements more incompatible than $\operatorname{Pr}(\mathrm{Pb}, \mathrm{Ce}, \mathrm{La}, \mathrm{Ta}, \mathrm{Nb}, \mathrm{U}, \mathrm{Th}$, $\mathrm{Ba}, \mathrm{Rb}$, and $\mathrm{Cs}$ ), there are variations consistent with the different components of the averages, although they overlap within error with the exception of Cs. ALL NORMAL MORB is $\sim 15 \%$ lower in incompatible element concentration than ALL MORB, showing that the plume influence acts to enrich only the most incompatible elements. ALL MORB is nearly identical to ALL MORB PLUS BAB except for $\mathrm{Pb}, \mathrm{Ba}, \mathrm{Rb}$, and $\mathrm{Cs}$ - fluid-mobile elements that are known to be enriched in many back-arc basins relative to open-ocean MORB. Therefore, ALL MORB PLUS BAB has lower $\mathrm{Ce} / \mathrm{Pb}, \mathrm{Rb} / \mathrm{Cs}$, and $\mathrm{Ba} / \mathrm{Cs}$ ratios. $\mathrm{Ba} / \mathrm{Rb}$ shows no difference between ALL MORB and ALL MORB PLUS BAB, perhaps suggesting a uniform contribution of $\mathrm{Ba}$ and $\mathrm{Rb}$ from the back-arcbasin signal.

[44] It is of interest to compare the new MORB averages with earlier estimates (Figure 6). The original calculations of average MORB by Hofmann [1988] and Sun and McDonough [1989] are far more depleted in highly incompatible elements than ALL MORB. For elements more compatible than Sr, however, the Hofmann [1988] estimate tracks the new estimate well.

[45] Su [2002], using an approach similar to this paper, showed for the first time a calculation of average MORB that was much more enriched in the highly incompatible elements. $A M$ [2010] provide a log-normal mean as their preferred estimate (cf. Table 2) $[A M, 2010]$, suggesting it is more enriched than previous models. They compare it to the "Normal Segments" and "Depleted Samples" average of $S u$ [2002] but overlooked his "All Segments" average. Their preferred values are in fact more depleted in the highly incompatible elements than $S u$ [2002] and more closely track the estimate by Hofmann [1988]. 
[46] The arithmetic mean of AM [2010], the "All Segments" average of $\mathrm{Su}$ [2002], and ALL MORB presented here are quite similar, differing by an average of only $13 \%$ (Figure $6 \mathrm{~b}$ ). ALL MORB is slightly less enriched in highly incompatible elements and more enriched in moderately incompatible elements, reflecting the spreading rate weighting that gives more weight to Pacific MORB. The similarities of the values, however, suggest that average MORB is now well established to be more enriched than the traditional concept of N-MORB. The methodology here, with segment length and spreading rate weighting factors and meaningful confidence estimates on the average values, should provide the most reliable estimate of average MORB (ALL MORB) to date.

\subsection{Normal MORB versus Depleted MORB}

[47] The significant change from previous results and usage is the new N-MORB composition, calculated as the log-normal mean (typical value) of segments more than $500 \mathrm{~km}$ from plumes. It is more enriched than earlier N-MORB estimates that were calculated using chemical, rather than distancefrom-hot spot, criteria [Hofmann, 1988; Sun and McDonough, 1989; AM, 2010]. Indeed for the highly incompatible elements, N-MORB in Table 3 is a factor of 3 more enriched than the N-MORB estimate by Sun and McDonough [1989] (Figure 7). The N-MORB estimate from Hofmann [1988] is the most similar to the new N-MORB composition but is still depleted in the most highly incompatible elements and enriched in the middleto-heavy rare earth elements (REE) relative to the new values.

[48] The previous literature values for N-MORB better represent the depleted end of the MORB compositional spectrum or D-MORB (Figure 7). This was first shown by Salters and Stracke [2004], as their estimate of D-MORB is similar to (and slightly more enriched than) the N-MORB of Sun and McDonough [1989]. The new D-MORB composition (Table 3), however, is even more enriched relative to the N-MORB value of Sun and McDonough [1989], demonstrating the extreme depletion in this early N-MORB estimate. The new D-MORB composition is quite similar to the "NMORB" composition of $A M$ [2010].

[49] In view of these results, it is evident that the N-MORB compositions entrenched in the literature are too depleted to accurately represent "normal MORB." The normal MORB composition calculated here is the most typical basalt composition erupted far from hot spots, truly "normal."

\subsection{Plume-Influenced MORB versus E- MORB}

[50] That N-MORB presented here is more enriched than previous estimates, even when plume segments have been eliminated, is indicative of a fundamental characteristic of the ridge system: enriched MORB are not necessarily near plumes. While this fact has been known from some of the earliest work on MORB [Kay et al., 1970; Allan et al., 1989; Langmuir et al., 1986; Donnelly et al., 2004; Cousens et al., 1995; Niu et al., 1999], the concept of a depleted upper mantle similar to previous N-MORB estimates remains ingrained. This is reflected, for example, in the common practice of normalizing trace element data to the Sun and McDonough [1989] N-MORB composition.

[51] To more fully explore whether plume influence is the preponderant enriched signal along ridges, we can investigate "plume segments" within $200 \mathrm{~km}$ of the hot spots tabulated by Courtillot et al. [2003] and compare them with other segments far from hot spots. The only hot-spot-influenced segments that meet this rather stringent criterion are near Jan Mayen, Iceland, Azores, Ascension, and Juan de Fuca/Cobb.

[52] The five hot spots have remarkable diversity in chemical influence (Figure 8a). For example, E-MORB segments $\left(\mathrm{La} / \mathrm{Sm}_{\mathrm{N}}>1.5\right)$ occur far more than $200 \mathrm{~km}$ away from Jan Mayen and the Azores. In contrast, none of the segments near Ascension and Juan de Fuca/Cobb are E-MORB segments. Near Iceland, the most robust hot spot, only one of the six proximal segments is also an E-MORB segment. An additional complexity is the number of E-MORB segments that do not have such close proximity to plumes, especially along the MAR and SWIR. This observation becomes even more robust when one considers individual samples with $\mathrm{La} / \mathrm{Sm}_{\mathrm{N}}>1.5$ (Figure 8b), as E-MORB then appear in greater number along the EPR and SEIR. It is clear, then, that while most plumes are enriched and produce a recognizable signal on nearby ridge segments, there is not a simple and universal relationship between plume segments and enriched segments, and vice versa.

[53] The lack of clear correspondence between plume-influenced segments and E-MORB segments leads to a notable difference between their mean chemistry. Figure 9 compares the log-normal composition of E-MORB segments defined using the 


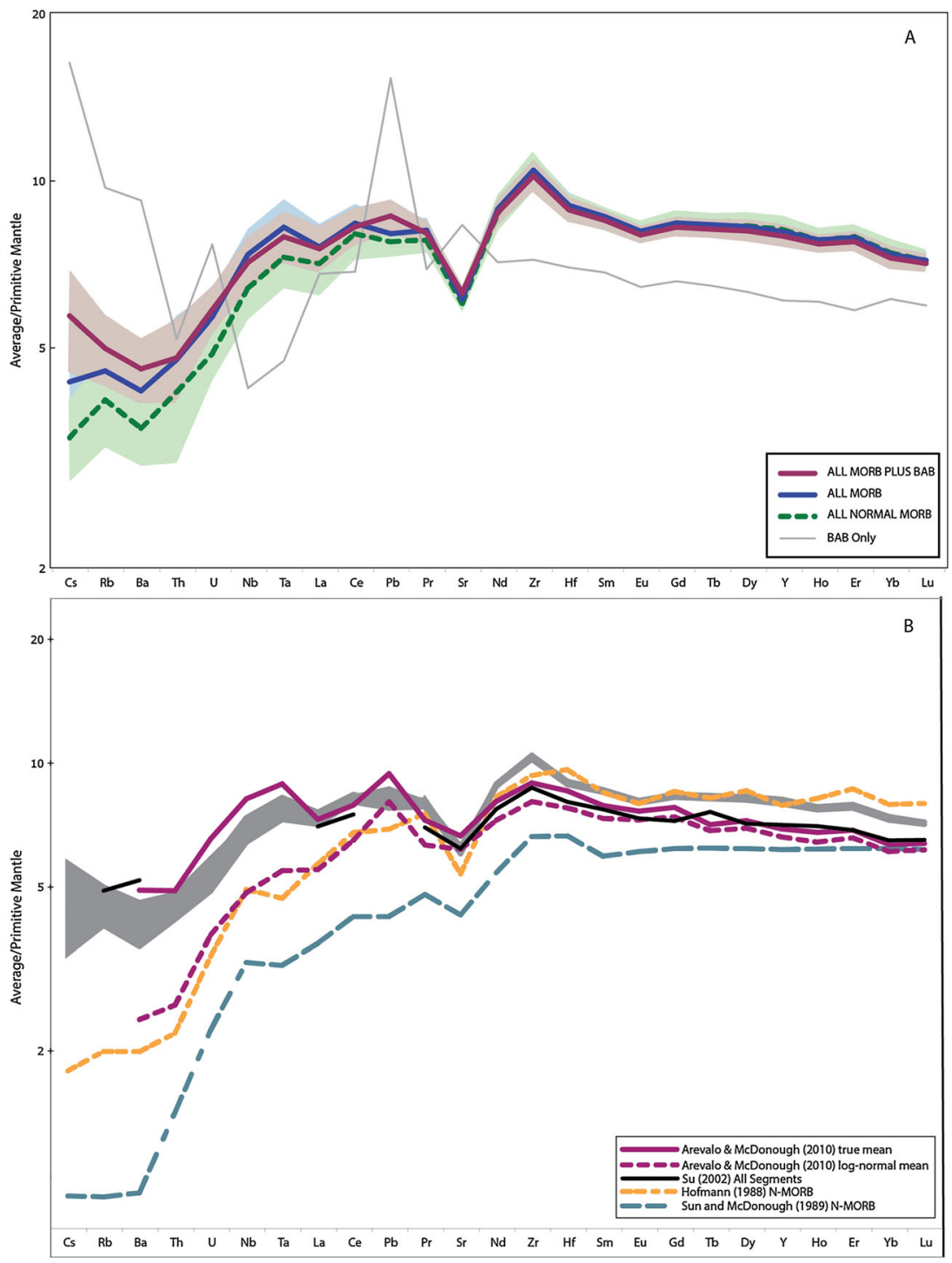

Figure 6. (A) Primitive mantle-normalized [Sun and McDonough, 1989] trace element patterns of the three global MORB compositions calculated in this study (ALL MORB, ALL MORB PLUS BAB, ALL NORMAL MORB), shown with shading indicating the $95 \%$ confidence interval on each mean composition. Note that the compositions are indistinguishable from each other in all elements more compatible than Pr. The ALL MORB PLUS BAB pattern is similar to the ALL MORB pattern except for pronounced peaks in the elements $\mathrm{Cs}, \mathrm{Rb}, \mathrm{Ba}$, and $\mathrm{Pb}$. These are fluid-mobile elements that are enhanced in back-arc basin basalts, as evidenced by the trace element pattern of BAB only. The ALL NORMAL MORB composition, calculated on segments $>500 \mathrm{~km}$ away from hot spots [Courtillot et al., 2003], is $\sim 15 \%$ depleted in the highly incompatible elements relative to the ALL MORB pattern. This shows the enriching effect of plumes on the highly incompatible element composition of nearby ridge basalts. (B) Comparison of the global averages in this study (shown in gray shading) to other estimates in the literature. Note the similarity between the All Segments average of $S u$ [2002] and the global MORB true mean estimate of AM [2010]. These two estimates are the most similar to the new global MORB compositions reported here, although slightly more enriched in highly incompatible elements and more depleted in moderately incompatible elements. The N-MORB estimates of Hofmann [1988] and Sun and McDonough [1989], and the log-normal estimate of AM [2010] are far more depleted than the global MORB compositions estimated in this study.

$\mathrm{La} / \mathrm{Sm}_{\mathrm{N}}$ classification scheme described above, with E-MORB segments defined by proximity to a hot spot (composition given in the Supporting Information). Given that plumes do not always lead to enriched ridge segments, it is no surprise that plume segments are significantly less enriched (e.g., $\mathrm{Ba}=56 \mathrm{ppm}$ ) than true E-MORB segments with $\mathrm{La} / \mathrm{Sm}_{\mathrm{N}}>1.5$ $(\mathrm{Ba}=125 \mathrm{ppm})$. Since enriched segments are not necessarily plume segments, E-MORB are best defined using the chemical definition, of $\mathrm{La} /$ $\mathrm{Sm}_{\mathrm{N}}>1.5$, rather than a spatial definition relative to hot spot locations. 
Table 3. The Compositions of N-MORB, D-MORB, and E-MORB ${ }^{\mathrm{a}}$

\begin{tabular}{|c|c|c|c|c|c|c|c|c|c|}
\hline & $\mathrm{n}$ & $\mathrm{N}^{-M O R B}{ }^{\mathrm{b}}$ & $\pm(95 \%$ conf $)$ & $\mathrm{n}$ & D-MORB & $\pm(95 \%$ conf $)$ & $\mathrm{n}$ & E-MORB & $\pm(95 \%$ conf $)$ \\
\hline $\mathrm{MgO}$ & 304 & 7.76 & 0.09 & 200 & 7.82 & 0.11 & 36 & 7.37 & 0.27 \\
\hline $\mathrm{SiO}_{2}$ & 304 & 50.42 & 0.08 & 200 & 50.39 & 0.08 & 36 & 50.58 & 0.33 \\
\hline $\mathrm{FeO}$ & 304 & 9.81 & 0.15 & 200 & 10.15 & 0.17 & 36 & 9.64 & 0.48 \\
\hline $\mathrm{CaO}$ & 304 & 11.35 & 0.08 & 200 & 11.49 & 0.09 & 36 & 11.18 & 0.27 \\
\hline $\mathrm{Na}_{2} \mathrm{O}$ & 304 & 2.83 & 0.05 & 200 & 2.71 & 0.05 & 36 & 2.72 & 0.18 \\
\hline $\mathrm{Al}_{2} \mathrm{O}_{3}$ & 304 & 15.13 & 0.12 & 200 & 14.93 & 0.12 & 36 & 14.94 & 0.38 \\
\hline $\mathrm{TiO}_{2}$ & 304 & 1.53 & 0.04 & 200 & 1.51 & 0.05 & 36 & 1.53 & 0.11 \\
\hline $\mathrm{K}_{2} \mathrm{O}$ & 304 & 0.140 & 0.011 & 200 & 0.096 & 0.007 & 36 & 0.394 & 0.075 \\
\hline $\mathrm{P}_{2} \mathrm{O}_{5}$ & 298 & 0.164 & 0.009 & 194 & 0.153 & 0.009 & 36 & 0.244 & 0.051 \\
\hline $\mathrm{MnO}$ & 272 & 0.171 & 0.004 & 171 & 0.178 & 0.006 & 35 & 0.165 & 0.013 \\
\hline $\mathrm{Ba}$ & 310 & 19.6 & 2.4 & 207 & 11.4 & 0.9 & 38 & 125.5 & 18.8 \\
\hline $\mathrm{Be}$ & 115 & 0.64 & 0.06 & 90 & 0.60 & 0.06 & 8 & 0.56 & 0.23 \\
\hline $\mathrm{Ce}$ & 323 & 12.42 & 0.72 & 224 & 10.01 & 0.57 & 37 & 25.52 & 3.73 \\
\hline Co & 272 & 42.3 & 0.5 & 193 & 43.6 & 0.5 & 34 & 41.7 & 1.6 \\
\hline $\mathrm{Cr}$ & 289 & 263 & 12 & 202 & 269 & 15 & 34 & 216 & 33 \\
\hline Cs & 199 & 0.024 & 0.004 & 142 & 0.015 & 0.002 & 28 & 0.124 & 0.024 \\
\hline $\mathrm{Cu}$ & 277 & 73 & 2 & 194 & 75 & 2 & 34 & 74 & 8 \\
\hline Dy & 324 & 5.50 & 0.18 & 224 & 5.48 & 0.18 & 37 & 4.62 & 0.21 \\
\hline $\mathrm{Er}$ & 323 & 3.42 & 0.11 & 223 & 3.46 & 0.11 & 37 & 2.75 & 0.12 \\
\hline $\mathrm{Eu}$ & 324 & 1.26 & 0.04 & 224 & 1.21 & 0.04 & 37 & 1.29 & 0.08 \\
\hline $\mathrm{Ga}$ & 224 & 17.0 & 0.2 & 177 & 16.9 & 0.2 & 27 & 17.3 & 0.7 \\
\hline $\mathrm{Gd}$ & 299 & 4.55 & 0.15 & 213 & 4.43 & 0.16 & 37 & 4.26 & 0.26 \\
\hline Hf & 313 & 2.46 & 0.10 & 218 & 2.31 & 0.14 & 37 & 2.54 & 0.26 \\
\hline Ho & 319 & 1.18 & 0.04 & 221 & 1.19 & 0.04 & 35 & 0.96 & 0.05 \\
\hline $\mathrm{La}$ & 326 & 4.19 & 0.29 & 225 & 3.12 & 0.19 & 38 & 12.02 & 1.66 \\
\hline $\mathrm{Li}$ & 192 & 6.1 & 0.2 & 153 & 6.1 & 0.2 & 22 & 5.3 & 0.6 \\
\hline $\mathrm{Lu}$ & 323 & 0.48 & 0.01 & 224 & 0.50 & 0.02 & 37 & 0.38 & 0.02 \\
\hline Mo & 128 & 0.36 & 0.04 & 97 & 0.30 & 0.03 & 21 & 0.76 & 0.21 \\
\hline $\mathrm{Nb}$ & 318 & 3.62 & 0.36 & 218 & 2.40 & 0.19 & 38 & 17.07 & 2.83 \\
\hline $\mathrm{Nd}$ & 331 & 10.66 & 0.45 & 225 & 9.46 & 0.45 & 38 & 14.86 & 1.33 \\
\hline $\mathrm{Ni}$ & 285 & 100 & 5 & 199 & 100 & 6 & 34 & 97 & 10 \\
\hline $\mathrm{Pb}$ & 291 & 0.51 & 0.03 & 204 & 0.43 & 0.02 & 35 & 0.98 & 0.14 \\
\hline $\operatorname{Pr}$ & 306 & 1.98 & 0.09 & 214 & 1.71 & 0.09 & 35 & 3.28 & 0.42 \\
\hline $\mathrm{Rb}$ & 299 & 1.84 & 0.25 & 195 & 1.05 & 0.10 & 38 & 10.56 & 1.47 \\
\hline $\mathrm{Sc}$ & 259 & 38.4 & 0.6 & 180 & 39.5 & 0.7 & 35 & 35.7 & 1.2 \\
\hline $\mathrm{Sm}$ & 330 & 3.48 & 0.12 & 225 & 3.32 & 0.13 & 38 & 3.72 & 0.28 \\
\hline $\mathrm{Sn}$ & 142 & 0.80 & 0.06 & 107 & 0.73 & 0.07 & 24 & 0.87 & 0.14 \\
\hline $\mathrm{Sr}$ & 328 & 128 & 5 & 223 & 111 & 3 & 37 & 207 & 22 \\
\hline $\mathrm{Ta}$ & 280 & 0.24 & 0.02 & 196 & 0.17 & 0.01 & 32 & 1.09 & 0.18 \\
\hline $\mathrm{Tb}$ & 312 & 0.82 & 0.03 & 217 & 0.82 & 0.03 & 35 & 0.73 & 0.04 \\
\hline $\mathrm{Th}$ & 311 & 0.252 & 0.029 & 213 & 0.156 & 0.013 & 36 & 1.367 & 0.232 \\
\hline $\mathrm{Tl}$ & 143 & 0.017 & 0.001 & 112 & 0.015 & 0.001 & 21 & 0.031 & 0.005 \\
\hline$T m^{\mathrm{b}}$ & & 0.52 & & & 0.52 & & & 0.41 & \\
\hline $\mathrm{U}$ & 292 & 0.083 & 0.008 & 203 & 0.055 & 0.005 & 36 & 0.386 & 0.061 \\
\hline $\mathrm{V}$ & 257 & 280 & 9 & 187 & 298 & 9 & 35 & 265 & 10 \\
\hline W & 150 & 0.08 & 0.01 & 117 & 0.07 & 0.01 & 23 & 0.31 & 0.07 \\
\hline $\mathrm{Y}$ & 323 & 33.2 & 1.2 & 222 & 33.2 & 1.1 & 37 & 26.6 & 1.1 \\
\hline $\mathrm{Yb}$ & 324 & 3.28 & 0.11 & 224 & 3.31 & 0.11 & 37 & 2.59 & 0.10 \\
\hline $\mathrm{Zn}$ & 261 & 85.3 & 2.3 & 189 & 88.1 & 2.5 & 29 & 82.4 & 6.1 \\
\hline $\mathrm{Zr}$ & 325 & 101.9 & 4.8 & 223 & 92.6 & 4.8 & 37 & 110.1 & 12.0 \\
\hline
\end{tabular}

${ }^{\mathrm{a}}$ In all three cases, the composition is calculated using the log-normal mean, weighted by segment length. N-MORB includes all possible segments except back-arc spreading centers and segments located $<500 \mathrm{~km}$ from a hot spot. It is identical to the log-normal mean provided for ALL NORMAL MORB in Table 2. D-MORB is calculated using segments that have $\mathrm{La} / \mathrm{Sm}_{\mathrm{N}}<0.8$, excluding back-arc spreading centers, and E-MORB is calculated using segments with $\mathrm{La} / \mathrm{Sm}_{\mathrm{N}}>1.5$, excluding back-arc spreading centers. The column labeled " $\mathrm{n}$ " indicates the number of segments used to determine the global mean compositions.

${ }^{\mathrm{b}} \mathrm{Tm}$ value (in italics) extrapolated from the $\mathrm{Er}$ and $\mathrm{Yb}$ values.

\subsection{Back-arc Basins}

[54] The back-arc basin (BAB) average includes data from the Lau (including new ICP-MS data),
Manus, Marianas, Scotia, and Woodlark basins (Table 2, 4). BAB are derived from an environment intermediate between mid-ocean ridges and island 


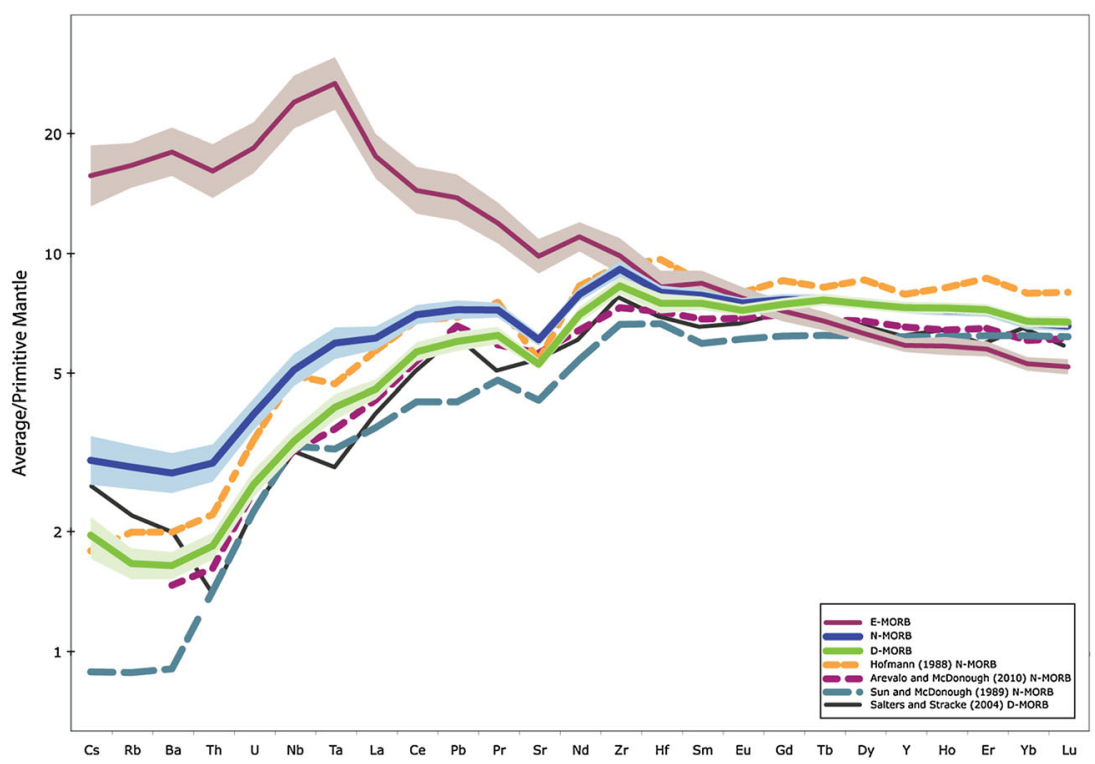

Figure 7. Trace element patterns of the E-MORB, N-MORB, and D-MORB (enriched, normal, and depleted MORB) compositions reported in this study, compared with earlier estimates. The E-MORB pattern is characterized by a strong enrichment in the highly incompatible elements and a depletion in the middle to heavy REE, crossing over the REE patterns of the N- and D-MORB. The N-MORB in this study, calculated as the log-normal mean (most typical value) of segments $>500 \mathrm{~km}$ from a plume, is more enriched than previously suggested; other published values for N-MORB better approximate D-MORB. Note that the N-MORB of Sun and McDonough [1989], however, is even more depleted than the new estimate for D-MORB.

arcs, with an important influence of $\mathrm{H}_{2} \mathrm{O}$ that differs from open ocean ridges [Langmuir et al., 2006]. Water affects the extent of melting [e.g., Burnham and Davis, 1974; Hirth and Kohlstedt, 1996; Gaetani and Grove, 1998], the saturation of phases during fractionation, and the delivery of fluid-mobile incompatible elements [Asimow et al., 2004]. Many of these effects are apparent in the average BAB major and trace element compositions.

\subsubsection{BAB Major Elements}

[55] In comparison with the ALL MORB average, the $\mathrm{BAB}$ average has distinctly lower $\mathrm{MgO}$ and $\mathrm{TiO}_{2}$ and higher $\mathrm{SiO}_{2}$ and $\mathrm{K}_{2} \mathrm{O}$ (Table 2). BAB basalts also have slightly lower $\mathrm{FeO}$ and $\mathrm{CaO}$ and higher $\mathrm{Al}_{2} \mathrm{O}_{3}$, although these values overlap ALL MORB within error. These characteristics, in particular low $\mathrm{MgO}, \mathrm{TiO}_{2}$, and $\mathrm{FeO}$ coupled with high $\mathrm{SiO}_{2}$ and $\mathrm{Al}_{2} \mathrm{O}_{3}$ of $\mathrm{BAB}$ basalts relative to openocean MORB have been documented previously [e.g., Sinton and Fryer, 1987; Langmuir et al., 2006, and references therein]. The lower $\mathrm{FeO}$ and $\mathrm{TiO}_{2}$ with higher $\mathrm{Al}_{2} \mathrm{O}_{3}$ at low $\mathrm{MgO}$ are particularly noteworthy, because if plagioclase + olivine are crystallizing, $\mathrm{FeO}$ and $\mathrm{TiO}_{2}$ increase and $\mathrm{Al}_{2} \mathrm{O}_{3}$ decreases. With such a low mean $\mathrm{MgO}$ content (6.67) relative to global $\mathrm{MORB}, \mathrm{TiO}_{2}$ and $\mathrm{FeO}$ contents would be expected to be higher in $\mathrm{BAB}$, with $\mathrm{Al}_{2} \mathrm{O}_{3}$ contents lower.

[56] The onset of plagioclase crystallization is delayed in hydrous conditions, which could account partially for the higher $\mathrm{Al}_{2} \mathrm{O}_{3}$ and lower $\mathrm{FeO}$ and $\mathrm{TiO}_{2}$ contents in $\mathrm{BAB}$ [Asimow et al., 2004]. Langmuir et al. [2006] showed, however, that the low $\mathrm{FeO}$ and $\mathrm{TiO}_{2}$ persist in $\mathrm{BAB}$ data even when the delayed plagioclase effect is taken into account, result jng instead from greater extents of melting at low pressures caused by the higher water contents [Langmuir et al., 2006]. Therein lies a fundamental distinction between $\mathrm{BAB}$ and open-ocean MORB: the relationship between $\mathrm{H}_{2} \mathrm{O}$ and extent of melting $(\mathrm{F})$. In the mid-ocean ridge environment, water acts to decrease the mean $\mathrm{F}$ of the melting regime; in $\mathrm{BAB}$, water increases $\mathrm{F}$ [Langmuir et al., 2006]. As we show below, the trace elements are also consistent with the interpretation that $\mathrm{BAB}$ basalts have been derived by higher F.

\subsubsection{BAB Trace Elements}

[57] Two main features of the average trace element composition of $\mathrm{BAB}$ are (1) the distinctly low concentrations of moderately incompatible trace elements and (2) the pronounced peaks in certain trace elements, deviating sharply from the global MORB 


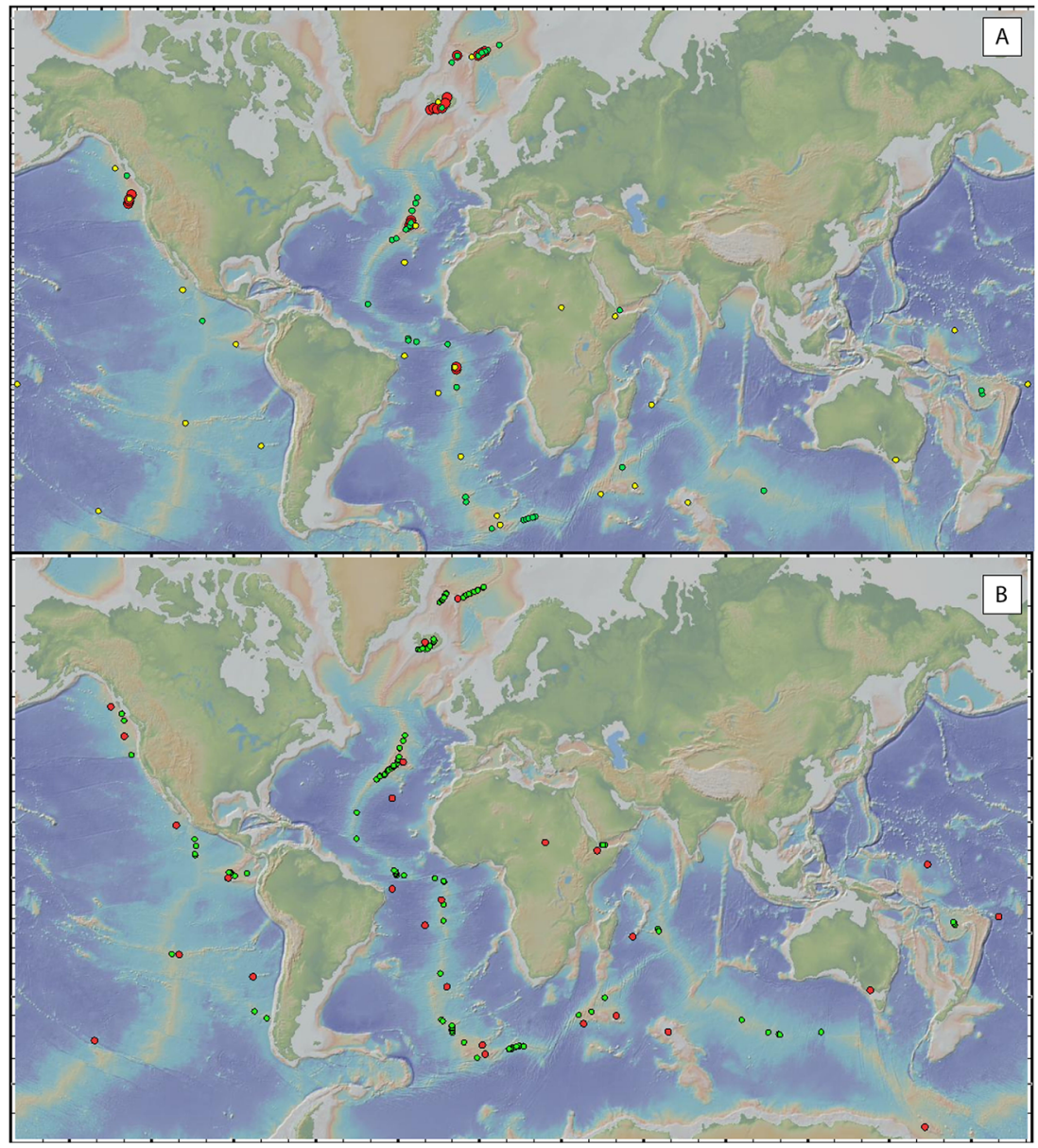

Figure 8. (A) Map showing the location of hot spots near ridges [Courtillot et al., 2003] in yellow circles, the location of E-MORB segments (defined by having $\mathrm{La} / \mathrm{Sm}_{\mathrm{N}}>1.5$ ) in green circles, and plume segments (within $200 \mathrm{~km}$ of a hot spot) in red circles. There are five hot spots within $200 \mathrm{~km}$ of a ridge: Jan Mayen, Iceland, Azores, Ascension, and Juan de Fuca/ Cobb. Note that the expression of each plume along the ridge is highly variable. At Iceland, only one of the plume segments is an E-MORB segment. In contrast, there are E-MORB segments extending $>200 \mathrm{~km}$ away from the Azores. Plume segments are not necessarily enriched segments, and vice versa. (B) Map showing the location of E-MORB (individual sample locations) in green circles, with near-ridge hot spots shown for reference in red circles. Note how many E-MORB occur far from any known hot spot locations, especially along the SEIR and portions of the EPR and MAR.

trend (Figure 6a). The 20\% lower concentrations of moderately incompatible trace elements in $\mathrm{BAB}$ compared to global MORB are especially noteworthy because $\mathrm{BAB}$ basalts are more fractionated than MORB, which would tend to increase trace element concentrations. As with $\mathrm{TiO}_{2}$, the lower concentrations of moderately incompatible trace elements are consistent with higher average extents of melting at $\mathrm{BAB}$. Some source depletion of the BAB source is also indicated, however, by low $\mathrm{Zr} / \mathrm{Sm}, \mathrm{Zr} / \mathrm{Hf}$, and $\mathrm{Y} / \mathrm{Yb}$ ratios in $\mathrm{BAB}$ relative to MORB. Pronounced peaks in fluid-mobile elements $\mathrm{Cs}, \mathrm{Rb}, \mathrm{Ba}, \mathrm{U}, \mathrm{Pb}$, and $\mathrm{Sr}$ also are evident in the BAB pattern.

[58] The marked differences in trace element concentrations lead to distinct trace element ratios in $\mathrm{BAB}$ basalts relative to global MORB - high $\mathrm{Ba} / \mathrm{Th}$ and low $\mathrm{Nb} / \mathrm{U}, \mathrm{Ce} / \mathrm{Pb}$, and $\mathrm{Th} / \mathrm{U}$. There is interesting structure even within the fluid-mobile element ratios; $\mathrm{Ba} / \mathrm{Cs}$ and $\mathrm{Rb} / \mathrm{Cs}$ are low, but $\mathrm{Ba} / \mathrm{Rb}$ is indistinguishable from global MORB. It appears therefore that Cs is delivered preferentially by the fluid component affecting $\mathrm{BAB}$ and that $\mathrm{Ba}$ and $\mathrm{Rb}$ have similar fluid mobility. Using similar reasoning, high $\mathrm{K} / \mathrm{U}$ in $\mathrm{BAB}$ suggests that $\mathrm{K}$ is more fluid mobile than $\mathrm{U}$. The observed pattern of fluid-mobile element enrichment is very similar to the "wet component" calculated independently by Bézos et al. [2009] for the Lau basin.

\section{Geochemical Implications}

[59] The data presented here permit a large number of global and regional geochemical issues to be 


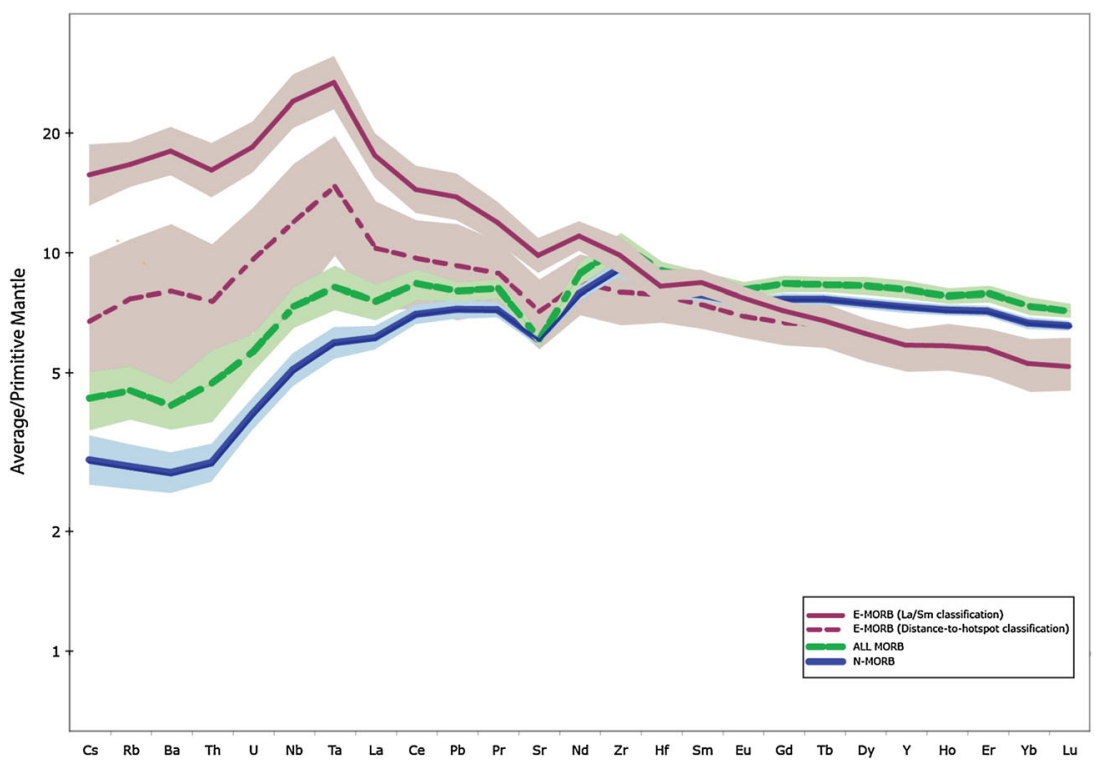

Figure 9. Primitive mantle-normalized [Sun and McDonough, 1989] trace element patterns for the E-MORB composition defined in this study (using $\mathrm{La} / \mathrm{Sm}_{\mathrm{N}}>1.5$ ) as well as a variant on this E-MORB classification, using hot spot proximity $(<200 \mathrm{~km})$ instead. Note that the "plume segment" E-MORB is less enriched than the chemically defined E-MORB. Also shown for comparison are the N-MORB and ALL MORB compositions determined in this study.

addressed. For example, there are indications that the Indian Ocean has some distinctive chemical features, such as low $\mathrm{Ce} / \mathrm{Pb}$ ratios [Rehkamper and Hofmann, 1997]. Is this a basin-wide phenomenon or does it have within-basin boundaries? Are there truly basin-scale compositional variations that are distinctive? What is the true influence of spreading rate on MORB compositions [e.g., Rubin and Sinton, 2007]? Is there any correspondence between isotopically defined provinces such as the Dupal anomaly [Hart, 1984] and major and trace element differences? Addressing many such questions is beyond the scope of this paper, but the raw data in the database and the segment averages will permit these and many other questions to be more definitively considered. Here we turn to two problems of significance for global Earth modelsthe question of the $\mathrm{K} / \mathrm{U}$ ratio of the mantle and the implications of the new average compositions for whether the silicate Earth has a chondritic $\mathrm{Sm} / \mathrm{Nd}$ ratio or instead is significantly depleted (higher $\mathrm{Sm} /$ Nd) relative to chondrites [Boyet and Carlson, 2005].

\subsection{K/U Ratio}

[60] The K/U ratio places powerful constraints on Earth's heat budget and noble gas abundances [Lassiter, 2004; Albarede, 1998; Davies, 1999; Jochum et al., 1983]. A reliable estimate of the average K/U of MORB constrains the $\mathrm{K} / \mathrm{U}$ of the upper mantle because $\mathrm{K}$ and $\mathrm{U}$ behave similarly during partial melting and crystal fractionation [e.g., Hofmann et al., 1986].

[61] Our best estimate (Table 1) for the $\mathrm{K} / \mathrm{U}$ ratio of MORB is $12,340 \pm 810$ (back arcs excluded). This value is calculated by dividing global segment average $\mathrm{K}$ by global segment average $\mathrm{U}$ concentrations. The bootstrapping approach described in section 3.3 uses 1000 trials to provide an estimate of uncertainty. As with all trace element ratios reported in this paper, only ridge segments for which both $\mathrm{K}$ and $\mathrm{U}$ are available were used to determine the global $\mathrm{K} / \mathrm{U}$ ratio. This estimate is nearly identical to the early estimate by Jochum et al. $[1983](\mathrm{K} / \mathrm{U}=12,700 \pm 200)$.

[62] This method for calculating trace element ratios yields a different result than if we had instead averaged the individual $\mathrm{K} / \mathrm{U}$ ratios of all segments or samples, since in the calculation above, a segment with the same $\mathrm{K} / \mathrm{U}$ but a higher overall concentration has a larger weighting on the mean $\mathrm{K} / \mathrm{U}$ ratio. Averaging ratios is appropriate to address the question, "What is the average $\mathrm{K} / \mathrm{U}$ of basalts erupting at ridges?" To constrain the MORB reservoir ratio, it is necessary to account for the variable concentrations of each element. Calculating MORB K/U using average(K)/ average $(\mathrm{U})$ instead of average $(\mathrm{K} / \mathrm{U})$ properly accounts for the effects of variable segment concentrations on the global ratios while eliminating the need for extremely precise $\mathrm{K} / \mathrm{U}$ ratios on depleted samples. 
[63] Of course, the $\mathrm{K}$ and $\mathrm{U}$ concentrations reflect both the mantle source and the extent of melting, but source variations are far more important. The mean extent of melting differs between segments by a factor of 2-3 [e.g., Klein and Langmuir, 1987], which will affect $\mathrm{K}$ and $\mathrm{U}$ concentrations by at most a factor of 3 . Since global variations in segment-average $\mathrm{K}$ are a factor of 100 and in segment-average $\mathrm{U}$ a factor of 200 , the $\mathrm{K}$ and $\mathrm{U}$ abundances are much more strongly controlled by mantle source variations than by extent of melting. Therefore, weighting the $\mathrm{K} / \mathrm{U}$ ratio by $\mathrm{K}$ and $\mathrm{U}$ concentrations is justified.

[64] A possible criticism of the ratios reported here is that most of the $\mathrm{K}$ data were measured by electron microprobe, which is not particularly precise at low $\mathrm{K}$ concentrations unless great care is taken in the analysis. It is therefore necessary to investigate the validity of the EMP K data.

[65] In order to assess the errors that might be associated with reliance on EMP data, 373 analyses from the Langmuir laboratory for which $\mathrm{K}$ was measured by both high precision (either DCP or solution ICPMS) and lower precision (EMP) can be compared. The data come from several regions, including the East Pacific Rise, the Gakkel Ridge, and the Mid-Atlantic Ridge. Figure 10a demonstrates that $\mathrm{K}$ determined by EMP and by ICP or DCP are consistent (with the exception of four analyses). Moreover, the same regional trends in $\mathrm{K}$ versus $\mathrm{U}$ are captured using both DCP or ICP K data and EMP $\mathrm{K}$ data (Figure 10b). This consistency is confirmed by a comparison of segment averages. For the 23 segments for which $\mathrm{K}$ has been measured by both DCP or ICP and EMP, the DCP-ICP and EMP-based $\mathrm{K}$ segment averages agree to better than $9 \%$ in all but four cases (Figure 10c). The largest deviation is a $27 \%$ offset for a highly depleted segment with ICP $\mathrm{K}_{2} \mathrm{O}$ of 0.08 wt. $\%$ and EMP $\mathrm{K}_{2} \mathrm{O}$ of 0.1 wt. \%.

[66] Another concern could be that there can be large errors on ratios for segments with low concentration samples measured by EMP. However, ratios based on low concentrations have a very low weighting in the overall calculation, because by taking average (K)/average (U), a segment with 0.3 wt. $\% \mathrm{~K}$ is 15 times more important than a segment with $0.02 \mathrm{wt} . \% \mathrm{~K}$. Therefore, the $\mathrm{K} / \mathrm{U}$ average of this paper is robust and not a result of EMP data being less precise.

[67] We emphasize these points because of the large difference between the value calculated in this paper and that reported recently by Arevalo et al. [2009], hereafter $A M L$ [2009], who suggested a $\mathrm{K} / \mathrm{U}$ ratio of the "composite MORB source" (which they also refer to as DMM), of 19,000 $\pm 2,600$, significantly higher than the estimate of this paper $(12,340 \pm 810)$. The reasons for this discrepancy are explored below.

(1) Data selection and coverage. The $\mathrm{K} / \mathrm{U}$ ratio of this study is determined from 2320 samples that are located within $10 \mathrm{~km}$ of a ridge segment axis. In contrast, $A M L$ [2009] used 87 samples for their determination of $\mathrm{K} / \mathrm{U}$. Of these 87 samples, 43 are excluded from this study because they are located $>10 \mathrm{~km}$ off-axis. This contrast is not a major factor in the different results, however.

(2) The calculation of the mean $K / U$ ratio. $A M L$ [2009] calculate the global K/U value by averaging the individual $\mathrm{K} / \mathrm{U}$ ratios of their 87 samples. This may provide the most likely $\mathrm{K} / \mathrm{U}$ ratio to be encountered when sampling a basalt but does not correctly constrain the MORB reservoir value. For example, calculating average $(\mathrm{K})$ /average $(\mathrm{U})$ rather than average $(\mathrm{K} / \mathrm{U})$ decreases the $\mathrm{K} / \mathrm{U}$ of their E-MORB from 15,700 to 13,040 .

This effect is particularly important because high $\mathrm{K} /$ $\mathrm{U}$ ratios in the $A M L$ [2009] data set are found largely in samples with low U concentrations (Figure 11). Using average $(\mathrm{K} / \mathrm{U})$ gives a large weighting to these samples. In this respect, it is noteworthy that isotope dilution data on individual samples from Jochum et al. [1983] are offset from the $A M L$ [2009] data at low $\mathrm{U}$ concentrations, hovering around a $\mathrm{K} / \mathrm{U}$ ratio of $\sim 12,500$. More work is needed to clarify the $\mathrm{K} / \mathrm{U}$ ratios of very low $U$ samples.

(3) Weighting of $N-M O R B$ and E-MORB. $A M L$ [2009] calculate separate $\mathrm{K} / \mathrm{U}$ ratios for N-MORB and E-MORB and then apply a weighted average of those ratios to determine the global K/U ratio for MORB: $95 \%$ $\mathrm{N}-\mathrm{MORB}+5 \%$ E-MORB. To select the individual samples that will contribute to the E-MORB value, $A M L$ [2009] use an unnormalized $\mathrm{La} / \mathrm{Sm} \geq 1$. Figure $12 \mathrm{a}$ shows the distribution of segment-average $\mathrm{La} / \mathrm{Sm}$ values in our global database. More than $67 \%$ of the segments have $\mathrm{La} / \mathrm{Sm} \geq 1$, a much larger percentage than the 5\% weight that $A M L$ [2009] assign to their E-MORB values. This discrepancy exists even at the individual segment scale. For example, $60 \%$ of the samples located in the MARK segment of the Mid-Atlantic Ridge, a canonical N-MORB segment, have $\mathrm{La} / \mathrm{Sm} \geq 1$ (Figure 12b). Assigning 5\% weight 

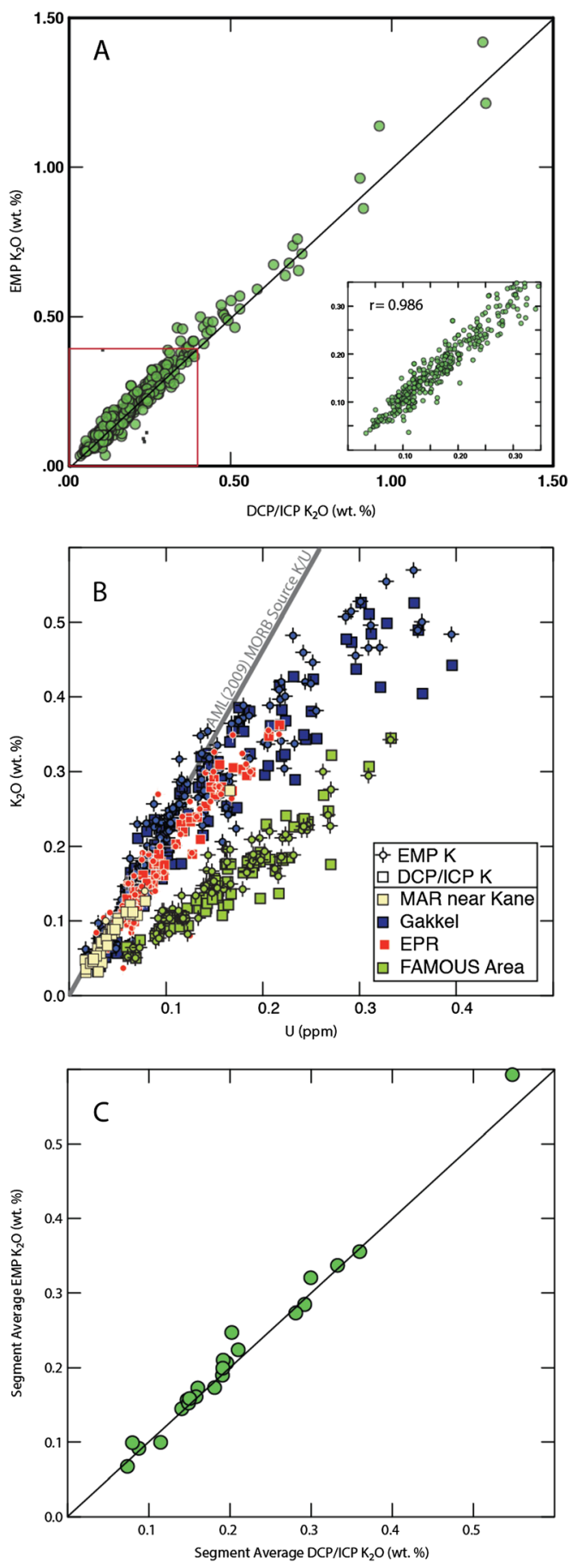

Figure 10. (A) Comparison of $\mathrm{K}_{2} \mathrm{O}$ measured by EMP to $\mathrm{K}_{2} \mathrm{O}$ measured by higher-precision techniques including DCP and ICP-MS in the Langmuir laboratory. Over a wide range of $\mathrm{K}_{2} \mathrm{O}$ contents, the measured values are remarkably coherent (with the exception of four samples, shown as small black squares, that were likely mislabeled). A 1:1 line is shown for reference. Inset shows depleted $\mathrm{K}_{2} \mathrm{O}$ values from 0 to 0.35 , which are characterized by an R-value of 0.986. (B) $\mathrm{K}_{2} \mathrm{O}$ (measured by EMP and DCP or ICP-MS) versus $\mathrm{U}$ for samples from a wide geographic range measured in the Langmuir laboratory. Note that regional differences in $\mathrm{K} / \mathrm{U}$ are captured whether $\mathrm{K}_{2} \mathrm{O}$ is measured by EMP or DCP/ICP. For reference, the K/U ratio estimated by $A M L$ [2009] for the "MORB Source" is shown. Note that the $A M L$ [2009] ratio is at the very depleted end of the MORB spectrum and is not representative of the mean MORB source. (C) Comparison of mean $\mathrm{K}_{2} \mathrm{O}$ calculated using EMP data versus mean $\mathrm{K}_{2} \mathrm{O}$ calculated using DCP or ICP-MS data for 23 ridge segments containing samples with $\mathrm{K}_{2} \mathrm{O}$ measured by both techniques in the Langmuir laboratory. Also shown is a 1:1 line for reference. Note how coherent the calculated mean $\mathrm{K}_{2} \mathrm{O}$ values are using both techniques, with 19 of 23 segment values agreeing to better than $9 \%$. 
to samples with $\mathrm{La} / \mathrm{Sm} \geq 1$ therefore significantly under-emphasizes the contribution of those samples to the global mean $\mathrm{K} / \mathrm{U}$ ratio and significantly over-emphasizes the contribution of samples with low $\mathrm{La} / \mathrm{Sm}$. Because the low $\mathrm{La} / \mathrm{Sm}$ samples reported by $A M L$ [2009] have high $\mathrm{K} / \mathrm{U}$ ratios, their large weighting results in a higher global $\mathrm{K} / \mathrm{U}$ ratio than would be obtained if the weighting factors more closely reflected the distribution of $\mathrm{La} /$ Sm ratios in the global MORB population.

[68] If the $\mathrm{K} / \mathrm{U}$ for the $A M L$ [2009] data set is recalculated using average $(\mathrm{K}) /$ average $(\mathrm{U})$ with a $\mathrm{La} / \mathrm{Sm}$ weighting that accurately reflects the global database, then the calculated average $\mathrm{K} / \mathrm{U}$ is 13,660 . This re-calculated $A M L$ [2009] value overlaps, within uncertainty, the global $\mathrm{K} / \mathrm{U}$ ratio reported here of 12,340 . Thus, the global MORB K/U ratio can be determined using either the present data set or the $A M L$ [2009] data set alone to be $\sim 13,000$, in agreement with earlier estimates [e.g., Jochum et al., 1983].

\section{2. $\mathrm{Sm} / \mathrm{Nd}$ Ratio}

[69] There are two long-standing paradigms of Earth's composition and structure. One is a chondritic composition for the bulk silicate Earth in refractory lithophile elements such as the REE [e. g., McDonough and Sun, 1995], and another is a complementary relationship between a depleted upper mantle and the continental crust [e.g., Jacobsen and Wasserburg, 1979; O'Nions et al., 1979]. The first of these paradigms has been called into question based on recent measurements showing that Earth has a ${ }^{142} \mathrm{Nd} /{ }^{144} \mathrm{Nd}$ excess relative to carbonaceous chondrites [e.g., Boyet and Carlson, 2005, 2006; Caro and Bourdon, 2010]. If Earth is made up of the materials represented by carbonaceous chondrites, then the ${ }^{142} \mathrm{Nd}$ excess is caused by the decay of the short-lived isotope ${ }^{146} \mathrm{Sm}$, and these data imply that the accessible silicate Earth is depleted in incompatible elements relative to chondrites. In this case, either (1) the Earth had a nonchondritic $\mathrm{Sm} / \mathrm{Nd}$ ratio from the beginning or (2) the Earth underwent an early differentiation event that created a high $\mathrm{Sm} / \mathrm{Nd}$ "Early Depleted Reservoir (EDR)" and a low Sm/Nd "Early Enriched Reservoir" [Carlson and Boyet, 2008].

[70] If the enriched reservoir is never sampled or otherwise lost, then the "predecessor to all modern terrestrial mantle reservoirs" is a non-chondritic, relatively depleted "primitive mantle," or EDR [Jackson and Carlson, 2011]. To account for the $\sim 18$ ppm excess in ${ }^{142} \mathrm{Nd} /{ }^{144} \mathrm{Nd}$ in terrestrial lavas relative to chondrites, the $\mathrm{Sm} / \mathrm{Nd}$ ratio of EDR is estimated to be $4.2-7.3 \%$ higher than chondrites [Jackson and Carlson, 2011], with uncertainties due to the $5 \mathrm{ppm}$ error on the $18 \mathrm{ppm}$ excess. Of course, ${ }^{146} \mathrm{Sm}$ is not the only radioactive isotope of Sm; ${ }^{147} \mathrm{Sm}$ also decays to ${ }^{143} \mathrm{Nd}$. The increase in the EDR $\mathrm{Sm} / \mathrm{Nd}$ ratio leads to a predicted ${ }^{143} \mathrm{Nd} /{ }^{144} \mathrm{Nd}$ for the "primitive mantle" or bulk silicate Earth of $0.5130 \pm 0.0001$ [Jackson and Carlson, 2012].

[71] An alternative explanation is that the ${ }^{142} \mathrm{Nd}$ excess is caused by nucleosynthetic anomalies. Ranen and Jacobsen [2006] suggested that the difference between chondrites and terrestrial rocks is related to incomplete mixing in the solar nebula and not to the decay of ${ }^{146} \mathrm{Sm}$. This position has been challenged, however [Andreasen and Sharma, 2006, 2007; Carlson et al., 2007; Qin et al., 2011].

[72] The mean composition of the ocean crust has an important bearing on these fundamental questions about Earth composition, because ocean ridge basalts provide by far the most voluminous sampling of the upper mantle and the best constraints on its composition. In order to preserve the paradigm of a complementary relationship between continental crust and upper mantle: (1) MORB mantle should be more depleted than the proposed depleted bulk silicate Earth in both $\mathrm{Sm} / \mathrm{Nd}$ and ${ }^{143} \mathrm{Nd} /{ }^{144} \mathrm{Nd}$. (2) There should be a reasonable mass balance and isotopic evolution relating MORB mantle and continental crust to the bulk silicate Earth composition.

[73] To address these predictions, we consider the average $\mathrm{Sm} / \mathrm{Nd}$ and ${ }^{143} \mathrm{Nd} /{ }^{144} \mathrm{Nd}$ ratios for global MORB, without any weighting by spreading rate. The rationale is that ridges sample mantle directly beneath them, so the average mantle composition (in contrast to the average crustal composition) is the average composition sampled along the length of the ridge system. For example, if the East Pacific Rise slowed in spreading rate by a factor of two, it would still be sampling the same mantle and have the same source $\mathrm{Sm} / \mathrm{Nd}$ and ${ }^{143} \mathrm{Nd} /{ }^{144} \mathrm{Nd}$.

[74] A complexity in comparing the $\mathrm{Sm} / \mathrm{Nd}$ ratio in MORB to the estimated $\mathrm{Sm} / \mathrm{Nd}$ ratio for the depleted silicate Earth model is that the MORB $\mathrm{Sm} / \mathrm{Nd}$ must be inverted to the $\mathrm{Sm} / \mathrm{Nd}$ ratio of the mantle source to correct for the effects of partial melting. We estimate mantle source $\mathrm{Sm} /$ $\mathrm{Nd}$ assuming a non-modal batch melting (similar results to pooled fractional melting) using the mineralogy, p- and d-values in Gale et al. [2011]. The 


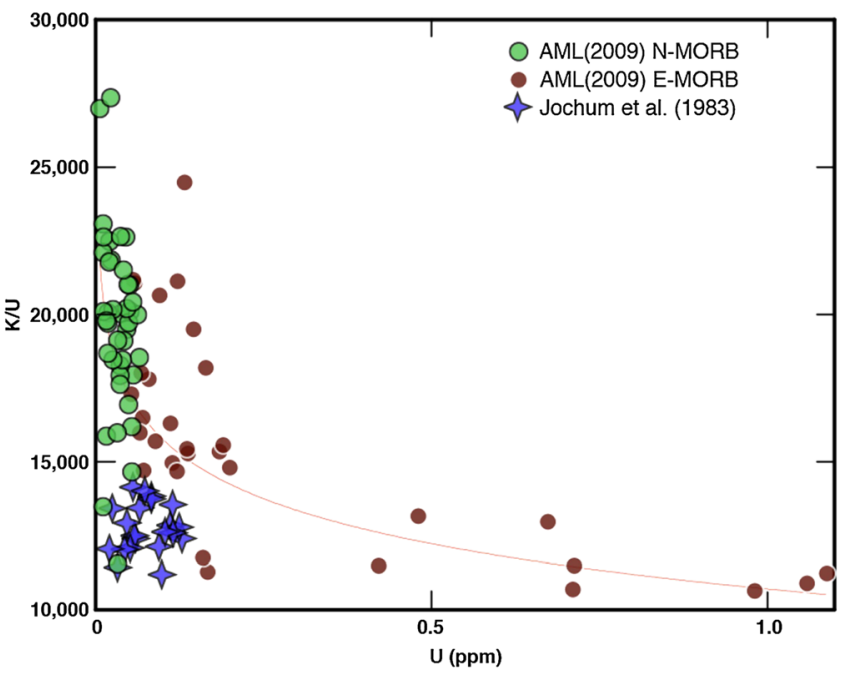

Figure 11. K/U versus $U$ in the $A M L$ [2009] data set (circles) compared to those measured by Jochum et al. [1983]. Note that the $A M L$ [2009] data show a change in $\mathrm{K} / \mathrm{U}$ with concentration, with higher $\mathrm{U}$ samples possessing a lower $\mathrm{K} / \mathrm{U}$ ratio. Interestingly, the K/U ratios of the enriched samples measured by $A M L$ [2009] are similar to those of the Jochum et al. [1983] samples. That K/U changes with concentration suggests that higher concentration samples should be weighted more strongly when estimating the MORB source $\mathrm{K} / \mathrm{U}$ ratio.

likely range of average extent of melting for MORB is between 8 and 15\% [e.g., Klein and Langmuir, 1987]. By 15\% melting, the MORB Sm/ $\mathrm{Nd}$ ratio is within $2 \%$ of the source ratio. ALL MORB $\mathrm{Sm} / \mathrm{Nd}$ is $0.319 \pm 0.005$, and the inverted source has $\mathrm{Sm} / \mathrm{Nd}<0.34$. Remarkably, the estimates for the $\mathrm{Sm} / \mathrm{Nd}$ ratio of the depleted silicate Earth model are between 0.342 and 0.352 (4.2-7.2\% higher than chondrites), substantially more depleted than global MORB, and similar to the inverted global MORB mantle source.

[75] Even for MORB from "normal segments" more than $500 \mathrm{~km}$ from any known hot spot, the mean $\mathrm{Sm} / \mathrm{Nd}$ ratio $=0.325 \pm 0.0046$, and the inverted mantle source again overlaps the proposed silicate Earth composition. These results are not dependent on the particular methodology of this paper. The $\mathrm{Sm} / \mathrm{Nd}$ ratio of global MORB in $\mathrm{Su}$ [2002] is 0.328, and the global mean and log-normal mean $\mathrm{Sm} / \mathrm{Nd}$ ratios in AM [2010] are 0.32 and 0.332, respectively. All studies concur that the current MORB mantle source in terms of $\mathrm{Sm} / \mathrm{Nd}$ ratio overlaps the estimate for the non-chondritic primitive mantle.

[76] One important caveat is that this simple inversion does not take into account melting complexities of the MORB source. For example, low-degree melts below the dry mantle solidus may contribute a substantial portion of the incompatible element budget and fractionate $\mathrm{Sm}$ from Nd more effectively. This might raise the $\mathrm{Sm} / \mathrm{Nd}$ of the mantle source slightly.
[77] The uncertainties inherent in source inversion can be avoided with mean MORB ${ }^{143} \mathrm{Nd} /{ }^{144} \mathrm{Nd}$, which may not be influenced by melting processes. Jackson and Carlson [2012] predict the isotopic range for "primitive mantle" to be between 0.5129 and 0.5131 . The mean ${ }^{143} \mathrm{Nd} /{ }^{144} \mathrm{Nd}$ for ALL MORB (excluding back arcs, $0.513057 \pm 0.000017$ ) and ALL NORMAL MORB (0.513072 \pm 0.000018$)$ fall within this range. The "All MORB" ${ }^{143} \mathrm{Nd} /{ }^{144} \mathrm{Nd}$ of 0.5131 estimated by Salters and Stracke [2004], with filters to exclude most plume-influenced segments, is also within the range of "EDR primitive mantle."

[78] The conclusion, then, is that the current MORBsource mantle overlaps the composition of the new estimated EDR. If MORB can be considered a representative sample of the upper mantle, then upper mantle $=$ EDR. In this case, there is no possibility of a complementary relationship between continental crust and oceanic upper mantle.

[79] There are two possible solutions to this paradox. The first and simplest is that Earth is chondritic in its $\mathrm{Sm} / \mathrm{Nd}$ composition. A second possibility is that there exists a more depleted mantle reservoir than is represented by simple inversion of average MORB. One way this could occur is if mantle melting beneath ridges preferentially samples enriched heterogeneities. Then the actual source would be more depleted than the sampled source. One difficulty with this option is that it requires melt segregation without mantle equilibration even when the total amount of 

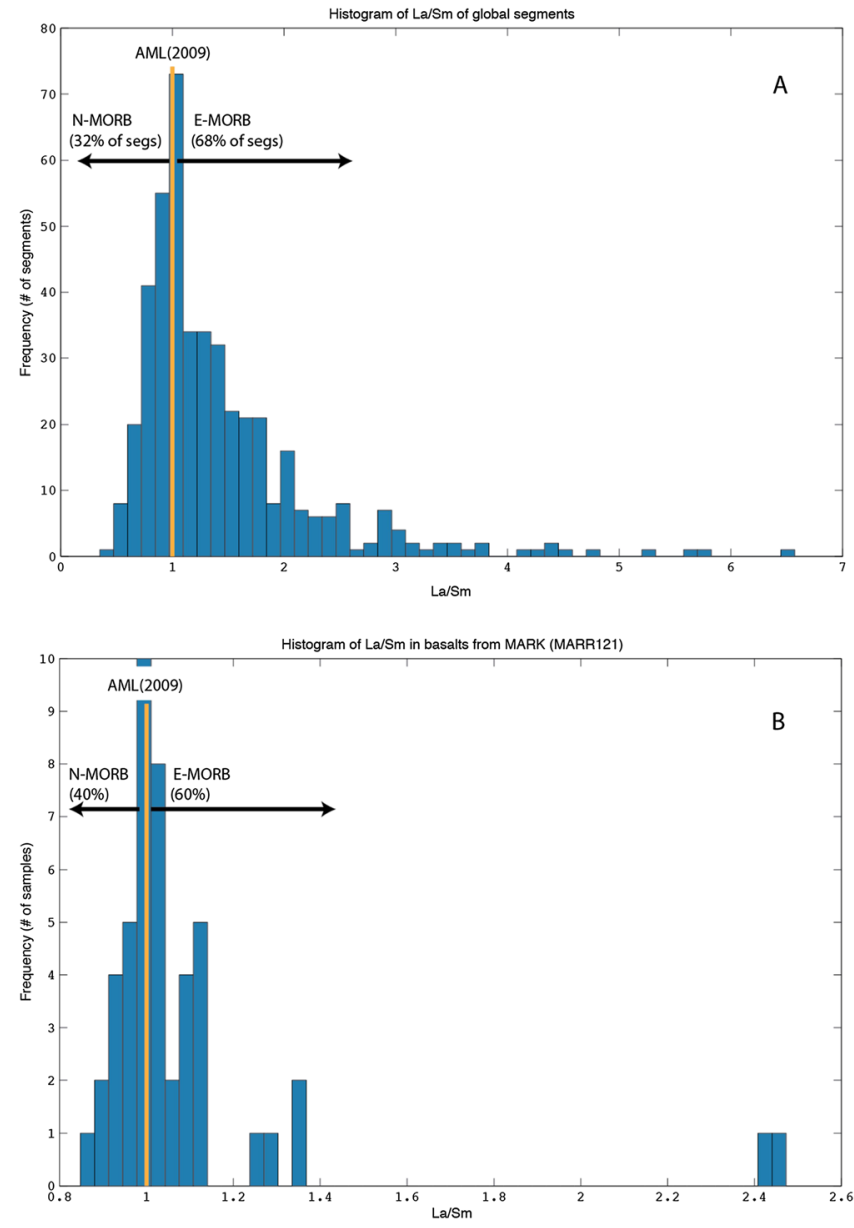

Figure 12. (A) Frequency distribution of the La/Sm (un-normalized) of segments in the global database. Using the definition of $A M L$ [2009] for E-MORB and N-MORB, 68\% of segments would be "E-MORB segments" and 32\% of segments would be "N-MORB segments." (B) Frequency distribution of the La/Sm (un-normalized) of individual samples from the MARK segment (MARR121 in the segment catalog), a canonical N-MORB segment. Note that even in this depleted segment, only $40 \%$ of the basalts have $\mathrm{La} / \mathrm{Sm}<1$. This demonstrates that the $95 \%$ mass contribution of N-MORB assumed in the modeling of $A M L$ [2009] requires modification.

melting is large, and it is not clear that this can occur. A further uncertainty is that the un-sampled portions of the mantle would be very depleted, and their low concentrations might not contribute significantly to the total mantle composition.

[80] Alternatively, it is possible that the mantle sampled by ocean ridges is more enriched than the "intermediate mantle," the region between the upper mantle sampled by ridges and the deep mantle likely sampled by plumes (Figure 13). As noted by Phipps Morgan and co-workers [Phipps Morgan and Morgan, 1999; Yamamoto et al., 2007, and references therein], plumes may traverse the mantle to be added to the uppermost mantle. Since mantle plumes are enriched, and may traverse the intermediate mantle without mixing, they would preferentially add enriched materials to the upper mantle. Ridges would sample this relatively enriched mantle. Crust created at ridges would then be processed at subduction zones, where continental crust would be created, leading to a relatively depleted recycled crust relative to the upper mantle composition. This depleted, recycled crust would preferentially accumulate in the intermediate mantle, leading to a deep depleted reservoir. The mantle would then have a three layer structure, enriched material at the core/ mantle boundary, an intermediate mantle that was depleted, and an only slightly depleted upper mantle. The extra depleted reservoir would be in the mantle at intermediate depths that would be undersampled by ridges.

[81] The simplest solution would be for Earth to be chondritic. Otherwise, it is necessary to postulate a ubiquitous disequilibrium melting process or another reservoir that is little sampled either by plumes or ridges. 


\section{Conclusions}

[82] This paper presents the most comprehensive compilation of MORB to date, including a detailed catalog of 771 global ridge segments, a major element database that has been interlaboratory bias corrected and re-normalized, and a predominantly ICP-MS trace element database manually checked for data quality with some 1100 newly published analyses. By calculating segment averages, issues with uneven sample distribution are mitigated, and both segment length and spreading rate can be weighted while calculating the mean global MORB compositions.

[83] Meaningful uncertainties are provided using the bootstrapping statistical technique that enables 95\% confidence intervals to be placed on mean concentrations and ratios. These approaches provide the most reliable and quantitative estimates of the mean composition of the ocean crust and a new classification of MORB. ALL MORB reflects the true mean composition of the zero age ocean crust apart from back-arc basins. N-MORB is the most likely composition encountered away from hot spots and back-arc basins. This definition of N-MORB differs from the widely used, highly depleted values that are not representative of ocean crust even far from hot spots. These global averages are significantly enriched relative to previous estimates. The concept of a highly depleted "normal ocean crust" should be abandoned.

[84] Two additional chemical classifications are also useful: D-MORB is the depleted end member of the MORB population. E-MORB is not well defined geographically as segments close to plumes, since some of these segments are not enriched. A chemical definition is the mean of all segments with $\mathrm{La} / \mathrm{Sm}_{\mathrm{N}}>1.5$.

[85] BAB basalts show enhanced $\mathrm{Cs}, \mathrm{Rb}, \mathrm{Ba}, \mathrm{U}$, $\mathrm{Pb}$, and $\mathrm{Sr}$, evidence of the "wet" arc component that delivers these fluid-mobile elements. They also possess noticeably lower mean concentrations of the moderately incompatible elements, demonstrating that the increased water at $\mathrm{BAB}$ also leads to higher extents of melting [Langmuir et al., 2006].

[86] The new global database permits a quantitative assessment of major geochemical problems associated with Earth composition and evolution. Two examples are:

(1) The K/U ratio of MORB, and by extension the MORB-source mantle, is $\sim 13,000$. The recent estimate of 19,000 by Arevalo et al. [2009] is unsubstantiated by the current study, and

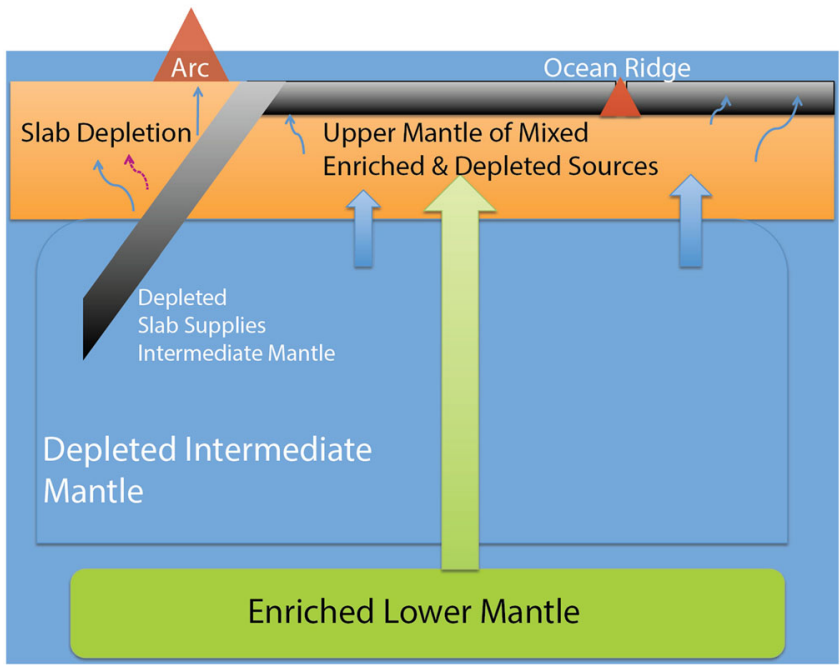

Figure 13. Cartoon illustrating one of the potential solutions to the paradox that the mean upper mantle composition equals the bulk silicate Earth composition proposed by Jackson and Carlson [2012]. Enriched reservoirs at the core mantle boundary give rise to plumes that ascend without interaction through the intermediate mantle. Low-degree melts also preferentially transport incompatible elements upwards. Both processes tend to enrich the upper mantle composition. Crust formed at ocean ridges samples this composition and is then recycled at subduction zones. There, continent extraction as well as possible extraction of deep, low-degree melts from the slab depletes the slab relative to the upper mantle. The depleted slab sinks through the upper mantle to accumulate in the intermediate mantle, between the enriched lower mantle and the mixed upper mantle. The upper mantle is a mixture between material supplied from the depleted intermediate mantle and enriched materials from plumes and low-degree melts. The deleted intermediate mantle would then provide the necessary depleted mantle complement to the continental crust. 
treatment of their data using the methodology of this paper provides a similar value to that reported here.

(2) The $\mathrm{Sm} / \mathrm{Nd}$ ratio estimated for the MORB-source mantle and the mean ${ }^{143} \mathrm{Nd} /{ }^{144} \mathrm{Nd}$ of MORB (even when excluding segments within $500 \mathrm{~km}$ of hot spots) overlaps those estimated for the "non-chondritic primitive mantle" [e.g., Jackson and Carlson, 2012]. A MORBsource mantle that is equivalent to the non-chondritic primitive mantle creates serious mass-balance issues for the silicate Earth, since continent extraction would somehow not have led to mantle depletion. Solutions are that Earth is chondritic or that MORB somehow sample a reservoir that is more enriched than most of the mantle.

\section{Acknowledgments}

[87] This manuscript benefited greatly from helpful conversations with Miaki Ishii, Sujoy Mukhopadhyay, and Richard O'Connell. Many people contributed to the ICP-MS data released in this paper, including Kerstin Lehnert, Katie Donnelly, Julien Foriel, Gad Soffer, Elizabeth Gier, Caitlin Rotman, Antoine Bézos, and Zhongxing Chen. We also sincerely appreciate the unpublished trace element data graciously provided by Jeffrey Standish and his advisor Henry Dick (thesis) and Antoine Bézos and his advisor Eric Humler (thesis) from SWIR, and by Stéphane Escrig from portions of the Lau basin and CIR. Christophe Hémond generously provided unpublished major element data from SEIR, and Antoine Bézos provided unpublished major element data from CIR. Jennifer Reynolds and Katie Donnelly are thanked for giving us permission to publish unpublished data from their theses. This manuscript greatly benefited from a thoughtful review by Emily Klein and from the editorial support from Thorsten Becker. This work was supported by NSF grants OCE-0752281 and OCE1061264.

\section{References}

Albarede, F. (1998), Time-dependent models of U-Th-He and $\mathrm{K}-\mathrm{Ar}$ evolution and the layering of mantle convection, Chem. Geol., 145(3-4), 413-429.

Allan, J. F., Batiza, R., Perfit, M. R., Fornari, D. J., and R. O. Sack (1989), Petrology of lavas from the Lamont seamount chain and adjacent East Pacific Rise, 10 degrees N, J. Petrol., 30(5), 1245-1298.

Andreasen, R., and M. Sharma (2006), Solar nebula heterogeneity in p-process samarium and neodymium isotopes, Science, 314 (5800), 806-809. DOI:10.1126/science.1131708

Andreasen, R., and M. Sharma (2007), Mixing and homogenization in the early solar system: Clues from $\mathrm{Sr}, \mathrm{Ba}, \mathrm{Nd}$, and Sm isotopes in meteorites, Astrophys. J., 665(1), 874-883. DOI: $10.1086 / 518819$.

Arevalo, R., Jr., and W. F. McDonough (2010), Chemical variations and regional diversity observed in MORB, Chem. Geol., 271(1-2), 70-85. DOI:10.1016/j.chemgeo.2009.12.013.
Arevalo, R., Jr., W. F. McDonough, and M. Luong (2009), The $\mathrm{K} / \mathrm{U}$ ratio of the silicate Earth: Insights into mantle composition, structure and thermal evolution, Earth Planet. Sci. Lett., 278(3-4), 361-369. DOI:10.1016/j.epsl.2008.12.023.

Argus, D. F., R. G. Gordon, and C. DeMets (2011), Geologically current motion of 56 plates relative to the no-net-rotation reference frame, Geochem. Geophys. Geosyst., 12. Q11001, 10.1029/2011GC003751.

Asimow, P. D., J. E. Dixon, and C. H. Langmuir (2004), A hydrous melting and fractionation model for mid-ocean ridge basalts: Application to the Mid-Atlantic Ridge near the Azores, Geochem. Geophys. Geosyst., 5. Q01E16, doi:10.1029/ 2003GC000568.

Bézos, A., S. Escrig, C. Langmuir, P. J. Michael, and P. D. Asimow (2009), Origins of chemical diversity of back-arc basin basalts: A segment-scale study of the Eastern Lau Spreading Center, J. Geophys. Res., 114, 1-25.

Bézos, A. (2003), Study of lithophile and siderophile elements (Ir, Ru, Pt and Pd) in mid-oceanic ridge basalts. Ph.D. Thesis.

Bird, P. (2003), An updated digital model of plate boundaries, Geochem. Geophys. Geosyst., 4. 1027, doi:10.1029/ 2001GC000252

Boyet, M., and R. W. Carlson (2005), 142Nd evidence for early $(>4.53 \mathrm{Ga})$ global differentiation of the silicate Earth, Science, 309, 576-581. DOI: 10.1126/science.1113634

Boyet, M., and R. W. Carlson (2006), A new geochemical model for the Earth's mantle inferred from $146 \mathrm{Sm}-142 \mathrm{Nd}$ systematics, Earth Planet. Sci. Lett., 250, 254-268. 10.1016/j.eps1.2006.07.046

Burnham, C. W., and N. F. Davis (1974), Role of H2O in silicate melts. 2. Thermodynamic and phase relations in system NaAlSi3O8-H2O to 10 kilobars, $700^{\circ} \mathrm{C}$ to $1100^{\circ} \mathrm{C}, \mathrm{Am}$. J. Sci., 274(8), 902-940.

Cannat, M., et al. (1999), Mid-Atlantic Ridge-Azores hotspot interactions: Along-axis migration of a hotspot-derived event of enhanced magmatism 10 to $3 \mathrm{Ma}$ ago, Earth Planet. Sci. Lett., 173(3), 257-269.

Carlson, R. W., and M. Boyet (2008), Composition of the Earth's interior: The importance of early events, Phil. Trans. Royal Soc.Mathematical Phys. Engineering Sci., 366(1883), 4077-4103. 10.1098/rsta.2008.0166

Carlson, R. W., M. Boyet, and M. Horan (2007), Chondrite barium, neodymium, and samarium isotopic heterogeneity and early earth differentiation, Science, 316(5828), 1175-1178. 10.1126/science. 1140189

Caro, G., and B. Bourdon (2010), Non-chondritic Sm/Nd ratio in the terrestrial planets: Consequences for the geochemical evolution of the mantle crust system, Geochim. Cosmochim. Acta, 74(11), 3333-3349. 10.1016/j.gca.2010.02.025

Courtillot, V., A. Davaille, J. Besse, and J. Stock (2003), Three distinct types of hotspots in the Earth's mantle, Earth Planet. Sci. Lett., 205(3-4), 295-308. 10.1016/S0012-821X(02) 01048-8

Cousens, B. L., J. F. Allan, M. I. Leybourne, R. L. Chase, and N. Vanwagoner (1995), Mixing of magmas from enriched and depleted mantle sources: The Northeast Pacific-WestValley segment, Juan de Fuca Ridge, Contributions Mineral. Petrol., 120(3-4), 337-357.

Crisp, J. A. (1984), Rates of magma emplacement and volcanic output, J. Volcanol. Geotherm. Res., 20, 177-211.

Davies, G. F. (1999), Geophysically constrained mantle mass flows and the (40)Ar budget: A degassed lower mantle?, Earth Planet. Sci. Lett., 166(3-4), 149-162.

Demets, C., R. G. Gordon, D. F. Argus, and S. Stein (1994), Effect of recent revisions to the geomagnetic reversal time- 
scale on estimates of current plate motions, Geophys. Res. Lett., 21(20), 2191-2194.

Devore, J., and R. Peck (2005), Statistics: The Exploration and Analysis of Data, Fifth ed., Brooks/Cole: Boston, MA.

Dixon, J. E., E. M. Stolper, and J. R. Holloway (1995), An experimental study of water and carbon dioxide solubilities in mid ocean ridge basaltic liquids. 1. Calibration and solubility models, J. Petrol., 36(6), 1607-1631.

Donnelly, K. E., S. L. Goldstein, C. H. Langmuir, and M. Spiegelman (2004), Origin of enriched ocean ridge basalts and implications for mantle dynamics, Earth Planet. Sci. Lett., 226(3-4), 347-366. DOI:10.1016/j.epsl.2004.07.019

Escartin, J., M. Cannat, G. Pouliquen, A. Rabain, and J. Lin (2001), Crustal thickness of V-shaped ridges south of the Azores: Interaction of the Mid-Atlantic Ridge (36 degrees39 degrees N) and the Azores hot spot, J. Geophys. Res.Sol. Earth, 106(B10), 21719-21735.

Fowler, C. M. R. (2008), The Solid Earth: An Introduction to Global Geophysics, Cambridge University Press: Cambridge, UK.

Gaetani, G. A., and T. L. Grove (1998), The influence of water on melting of mantle peridotite, ContributionsMineral. Petrol., 131 (4), 323-346.

Gale, A., S. Escrig, E. J. Gier, C. H. Langmuir, and S. L. Goldstein (2011), Enriched basalts at segment centers: The Lucky Strike $\left(37^{\circ} 17^{\prime} \mathrm{N}\right)$ and Menez Gwen $\left(37^{\circ} 50^{\prime} \mathrm{N}\right)$ segments of the MidAtlantic Ridge, Geochem. Geophys. Geosyst., 12. Q06016, 10.1029/2010GC003446

Hart, S. R. (1984), A large-scale isotope anomaly in the southern-hemisphere mantle, Nature, 309(5971), 753-757.

Hirth, G., and D. L. Kohlstedt (1996), Water in the oceanic upper mantle: Implications for rheology, melt extraction and the evolution of the lithosphere, Earth Planet. Sci. Lett., 144(1-2), 93-108.

Hofmann, A. W. (1988), Chemical differentiation of the Earth: The relationship between mantle, continental crust, and oceanic crust, Earth Planet. Sci. Lett., 90, 297-314.

Hofmann, A. W., K. P. Jochum, M. Seufert, and W. M. White (1986), $\mathrm{Nb}$ and $\mathrm{Pb}$ in oceanic basalts: New constraints on mantle evolution, Earth Planet. Sci. Lett., 79, 33-45.

Jackson, M. G., and R. W. Carlson (2011), An ancient recipe for flood-basalt genesis, Nature, 476(7360), 316-U377. doi:10.1038/nature 10326

Jackson, M. G., and R. W. Carlson (2012), Homogeneous superchondritic ${ }^{142} \mathrm{Nd} /{ }^{144} \mathrm{Nd}$ in the mid-ocean ridge basalt and ocean island basalt mantle, Geochem. Geophys. Geosyst., 13(Q01011), doi:10.1029/2012GC004114.

Jacobsen, S.B., and G. J. Wasserburg (1979), The mean age of mantle and crustal reservoirs, J. Geophys. Res., 84, 7411-7427.

Jenner, F. E., and H. S. C. O'Neill (2012), Analysis of 60 elements in 616 ocean floor basaltic glasses, Geochem. Geophys. Geosyst., 13. Q02005, 10.1029/2011GC004009.

Jochum, K. P., A. W. Hofmann, E. Ito, H. M. Seufert, and W. M. White (1983), K, U and Th in mid-ocean ridge basalt glasses and heat-production, $\mathrm{K} / \mathrm{U}$ and $\mathrm{K} / \mathrm{Rb}$ in the mantle, Nature, 306 (5942), 431-436.

Kay, R., Hubbard, N. J., and P. W. Gast (1970), Chemical characteristics and origin of oceanic ridge volcanic rocks, J. Geophys. Res.-Sol. Earth, 75(8), 1585.

Kelley, K. A., R., Kingsley, and J.-G. Schilling (2013), Composition of plume-influenced mid-ocean ridge lavas and glasses from the Mid-Atlantic Ridge, East Pacific Rise, Galápagos Spreading Center, and Gulf of Aden, Geochem.Geophys. Geosyst 14, 223-242doi: 10.1029/ 2012 GC004415.

Klein, E. M., and C. H. Langmuir (1987), Global correlations of ocean ridge basalt chemistry with axial depth and crustal thickness, JGR 92(B8), 8089-8115.
Klein, E. M., C. H. Langmuir, and H. Staudigel (1991), Geochemistry of basalts from the Southeast Indian Ridge, $115^{\circ} \mathrm{E}-138^{\circ}$-E, J. Geophys. Res.-Sol. Earth Planets, 96 (B2), 2089-2107.

Langmuir, C. H., J. F. Bender, and R. Batiza (1986), Petrological and tectonic segmentation of the East Pacific Rise, 5-degrees30'-14-degrees-30'-N, Nature, 322(6078), 422-429.

Langmuir, C. H., Bezos, A., Escrig, S. and Parman, S. W. (2006), Chemical systematics and hydrous melting of the mantle in back-arc basins, in Back-Arc Spreading Systems: Geological, Biological, Chemical and Physical Interactions, edited, American Geophysical Union: Geophysical Monograph Series 166, pp. 87-146, Washington, D. C.

Lassiter, J. C. (2004), Role of recycled oceanic crust in the potassium and argon budget of the Earth: Toward a resolution of the "missing argon" problem, Geochem. Geophys. Geosyst., 5. 10.1029/2004GC000711.

Lehnert, K., Y. Su, C. H. Langmuir, B. Sarbas, and U. Nohl (2000), A global geochemical database structure for rocks, Geochem. Geophys. Geosyst., 1, 1012.

Macdonald, K. C., D. S. Scheirer, and S. M. Carbotte (1991), Midocean ridges-Discontinuities, segments and giant cracks, Science, 253(5023), 986-99.

McDonough, W. F., and S. Sun (1995), The composition of the Earth, Chem. Geol. 120, 223-253.

Melson, W. G., T. O'Hearn, and E. Jarosewich (2002), A data brief on the Smithsonian Abyssal Volcanic Glass Data File, Geochem. Geophys. Geosyst., 3, 11. DOI: 10.1029/ $2001 \mathrm{GC} 000249$

Newman, S., and J. B. Lowenstern (2002), VOLATILECALC: A silicate melt-H2O-CO2 solution model written in Visual Basic for excel, Comput. Geosci., 28(5), 597-604. 10.1016/ S0098-3004(01)00081-4

Niu, Y. L., K. D. Collerson, R. Batiza, J. I. Wendt, and M. Regelous (1999), Origin of enriched-type mid-ocean ridge basalt at ridges far from mantle plumes: The East Pacific Rise at 11 degrees $20^{\prime}$ N, J. Geophys. Res.-Sol. Earth, 104(B4), 7067-7087.

O'Nions, R. K., N. M. Evensen, and P. J. Hamilton (1979), Geochemical modeling of mantle differentiation and crustal growth, J. Geophys. Res., 84(NB11), 6091-6101.

Phipps Morgan, J., and W. J. Morgan (1999), Two-stage melting and the geochemical evolution of the mantle: A recipe for mantle plum-pudding, Earth Planet. Sci. Lett., 170, 215-239.

Qin, L., R. W. Carlson, and C. M. O. D. Alexander (2011), Correlated nucleosynthetic isotopic variability in $\mathrm{Cr}, \mathrm{Sr}$, $\mathrm{Ba}, \mathrm{Sm}, \mathrm{Nd}$ and $\mathrm{Hf}$ in Murchison and QUE 97008, Geochim. Cosmochim. Acta, 75(24), 7806-7828. 10.1016/ j.gca.2011.10.009

Ranen, M. C., and S. B. Jacobsen (2006), Barium isotopes in chondritic meteorites: Implications for planetary reservoir models, Science, 314, 809-812. 10.1126/science.1132595

Rehkamper, M., and A. W. Hofmann (1997), Recycled ocean crust and sediment in Indian Ocean MORB, Earth Planet. Sci. Lett., 147(1-4), 93-106.

Rubin, K. H., and J. M. Sinton (2007), Inferences on midocean ridge thermal and magmatic structure from MORB compositions, Earth Planet. Sci. Lett., 260(1-2), 257-276. 10.1016/j.epsl.2007.05.035.

Ryan, W. B. F., et al. (2009), Global multi-resolution topography synthesis, Geochem. Geophys. Geosyst., 10, Q03014,10.1029/2008GC002332.

Salters, V. J. M., and A. Stracke (2004), Composition of the depleted mantle, Geochem. Geophys. Geosyst., 5(5), 27. 10.1029/2003GC000597.

Schilling, J. G. (1975), Azores mantle blob-rare-Earth evidence, Earth Planet. Sci. Lett., 25(2), 103-115. 
Schilling, J. G., and J. W. Winchester (1966), Rare earths in Hawaiian basalts, Science, 153(3738), 867.

Sinton, J. M., and P. Fryer (1987), Mariana trough lavas from $18^{\circ} \mathrm{N}$-Implications for the origin of back-arc basin basalts, J. Geophys. Res.-Sol. Earth Planets, 92(B12), 12782-12802.

Standish, J. (2005), The influence of ridge geometry on lithospheric accretion at ultraslow-spreading rates between $9^{\circ}-25^{\circ} \mathrm{E}$ on the Southwest Indian Ridge: Basalt composition sensitivity to local tectonomagmatic processes, Ph.D. Thesis, Massachusetts Institute of Technology.

Su, Y. (2002), Mid-ocean ridge basalt trace element systematics: Constraints from database management, ICP-MS analyses, global data compilation, and petrologic modeling, $\mathrm{Ph}$. D. Thesis, Columbia University.

Sun, S. S., and W. F. McDonough (1989), Chemical and isotopic systematics of oceanic basalts: Implications for mantle composition and processes, Geol.Soc., London, Spec. Publ., 42(1), 313-345.
Sun, S. S., R. W. Nesbitt, and A. Y. Sharaskin (1979), Geochemical characteristics of mid-ocean ridge basalts, Earth Planet. Sci. Lett., 44, 119-138.

Sun, W., Y. Hu, V. S. Kamenetsky, S. M. Eggins, M. Chen, and R. J. Arculus (2008), Constancy of $\mathrm{Nb} / \mathrm{U}$ in the mantle revisited, Geochim. Cosmochim. Acta, 72(14), 3542-3549. 10.1016/j.gca.2008.04.029

Sun, W. D., V. C. Bennett, S. M. Eggins, R. J. Arculus, and M. R. Perfit (2003), Rhenium systematics in submarine MORB and back-arc basin glasses: Laser ablation ICP-MS results, Chem. Geol., 196(1-4), 259-281. 10.1016/S0009-2541(02)00416-3.

Yamamoto, M., J. Phipps Morgan, and W. J. Morgan (2007), Global plume-fed asthenosphere flow-I: Motivation and model development, in Plates, Plumes and Planetary Processes, edited by G. R. Foulger and D. M. Jurdy, Geological Society of America Special Papers 430, p. 165-188, doi:10.1130/2007.2430(09). 